\title{
The NLR-related protein NWD1 is associated with prostate cancer and modulates androgen receptor signaling
}

\author{
Ricardo G. Correa ${ }^{1}$, Maryla Krajewska ${ }^{1}$, Carl F. Ware ${ }^{1}$, Motti Gerlic ${ }^{1,2}$ and John C. \\ Reed $^{1}$ \\ ${ }^{1}$ Sanford-Burnham Medical Research Institute, La Jolla, CA \\ ${ }^{2}$ Current address: Dept. of Clinical Microbiology and Immunology, Sackler Faculty of Medicine, Tel Aviv University, Tel Aviv, \\ Israel \\ Correspondence to: Ricardo G. Correa, email: rcorrea@sbmri.org \\ John C. Reed, email: reedoffice@sbmri.org
}

Keywords: NLR, PDEF, AR, SRY, prostate

Received: March 14, $2014 \quad$ Accepted: March 24, $2014 \quad$ Published: March 26, 2014

This is an open-access article distributed under the terms of the Creative Commons Attribution License, which permits unrestricted use, distribution, and reproduction in any medium, provided the original author and source are credited.

\section{ABSTRACT:}

Prostate cancer (PCa) is among the leading causes of cancer-related death in men. Androgen receptor (AR) signaling plays a seminal role in prostate development and homeostasis, and dysregulation of this pathway is intimately linked to prostate cancer pathogenesis and progression. Here, we identify the cytosolic NLR-related protein NWD1 as a novel modulator of AR signaling. We determined that expression of NWD1 becomes elevated during prostate cancer progression, based on analysis of primary tumor specimens. Experiments with cultured cells showed that NWD1 expression is up-regulated by the sex-determining region $Y$ (SRY) family proteins. Gene silencing procedures, in conjunction with transcriptional profiling, showed that NWD1 is required for expression of PDEF (prostate-derived Ets factor), which is known to bind and co-regulate AR. Of note, NWD1 modulates AR protein levels. Depleting NWD1 in PCa cell lines reduces AR levels and suppresses activity of androgendriven reporter genes. NWD1 knockdown potently suppressed growth of androgendependent LNCaP prostate cancer cells, thus showing its functional importance in an AR-dependent tumor cell model. Proteomic analysis suggested that NWD1 associates with various molecular chaperones commonly related to AR complexes. Altogether, these data suggest a role for tumor-associated over-expression of NWD1 in dysregulation of AR signaling in PCa.

\section{INTRODUCTION}

Prostate cancer $(\mathrm{PCa})$ is the most common noncutaneous cancer affecting men worldwide. According to the United States Cancer Statistics (USCS), $\mathrm{PCa}$ had the highest incidence rate in U.S. men from 2003 to 2007 among lethal forms of cancer, and ranked second as a cause of cancer-related death in the same period. Remarkably, about 2.8 million men in USA are potentially living with this condition (more than 2 percent of the current male population over 15 years old), where approximately 240,000 new cases were diagnosed in 2012 [1].

$\mathrm{PCa}$ progression involves many alterations in prostate epithelial cells that lead, in some cases, to an androgen deprivation-resistant phenotype (castrationresistant $\mathrm{PCa}, \mathrm{CRPC}$ ), which relates to a poor prognosis for patients. Amplification of the gene encoding the androgen receptor (AR), which typically acts as a transcription factor upon binding to androgenic hormones, occurs in approximately $80 \%$ of the CRPCa cases, representing the most common genetic alteration in this type of cancer [1]. In fact, the majority of PCa specimens in the setting of relapse from hormonal therapy expresses $\mathrm{AR}$ and these cancers remain dependent on AR signaling for proliferation and survival in the presence of castrate levels of androgens $[2,3]$. In this context, targeting AR signaling is still considered a critical component of the approach to therapy of metastatic PCa.

NLRs (NACHT and Leucine Rich Repeat domain 
containing proteins) constitute a major subfamily of innate immunity proteins $[4,5]$, mostly acting as cytosolic pattern recognition receptors (PRRs) involved in the detection of cytoplasmic pathogens (pathogen-associated molecular patterns, PAMPs) and endogenous cell injury signals (danger-associated molecular patterns, DAMPs) [6]. The recognition of activating ligands by NLRs initiates a variety of host defense pathways through the activation of $\mathrm{NF}-\kappa \mathrm{B}$, stress kinases, interferon response factors (IRFs) and/or inflammatory caspases [7-10]. Dysregulation of NLR activities has been described in a variety of maladies, including chronic inflammatory diseases and cancer predisposition $[11,12]$. For example, NOD1 (NLRC1) is among the NLR family members shown to possibly play a role in tumorigenesis. NOD1 stimulation induces apoptosis of MCF-7 breast carcinoma cells, and NOD1-deficient MCF-7 cells generate larger tumors when injected into immunocompromised mice [13]. Mice deficient in other NLR members, such as NLRP3 and NLRP12, have also been shown to be more susceptible to colitis-associated colon cancer $[12,14]$. Polymorphisms of the NLR genes NOD1 (NLRC1) and NOD2 (NLRC2) have been correlated with altered cancer risk. $N O D 1$ gene polymorphisms have been associated with a variety of cancer types, possibly due to the recognition by this innate immunity protein of ligands from $H$. pylori (etiologic agent in gastric cancer and MALT lymphoma), C. trachomatis (putative etiologic agent in ovarian cancer), $P$. acnes (possible causative agent in PCa) and C. pneumonia (plausible etiological agent in lung cancer) [15]. In addition, NOD1 and NOD2 have been shown to be fully operative in prostate epithelial cells and, in cooperation with TLRs, may elicit immune responses during PCa progression [16].

The NLR protein family is highly diverse across vertebrate species and invertebrate marine organisms, sharing structural similarity with plant disease-resistance (R) proteins involved in the hypersensitive response against plant pathogens [7, 17, 18]. The NLR protein structure is based on a $\mathrm{C}$-terminal leucine-rich repeat (LRR) domain that is involved in recognition of conserved microbial patterns or other ligands; a centrally located nucleotide-binding NACHT domain that mediates selfoligomerization and is essential for NLR activation; and a N-terminal effector domain, which is responsible for the interaction with adaptor molecules that result in signal transduction $[4,7,19,20]$. In humans, 22 NLRs have been described including 14 NLRPs with a PYRIN effector domain at the N-terminus, and 5 NLRCs whose effector domain is comprised of a caspase recruitment domain (CARD).

Based on genomic analysis of potential NLR family members found in other organisms, a newly conserved NACHT-domain protein with WD40 repeats has been identified in fish [21]. This protein, recently named as NWD1 (NACHT and WD repeat domain-containing protein 1), clustered with Apaf1 (Apoptotic peptidase activating factor 1), a cytoplasmic protein structurally similar to the NLRs that forms the apoptosome and mediates caspase- 9 activation in the context of apoptosis induction [22]. The N-terminal region of NWD1 contains no motifs known from other proteins but, similar to Apaf1, it possesses WD40 repeats instead of LRRs at the C-terminus. Interestingly, this newly found fish protein has orthologs in both mice and humans [21], neither of which had been previously characterized. Therefore, here we investigate NWD1's function and further correlate its expression as a potential PCa biomarker. Gene expression profiling and functional analysis suggest that NWD1 is involved in AR signaling and PCa progression, acting to stabilize steady-state AR protein levels in cells.

\section{RESULTS}

\section{Expression profiling and protein characteristics of NWD1}

The human NWD1 gene spans about 98 kilobases (kb), and is located on chromosome 19p13.11 (NCBI Gene ID 284434). This gene is comprised by 19 exons (GenBank NM_001007525.3), and its transcript coding sequence is about $4 \mathrm{~kb}$ (position 689 to 4765 from GenBank BC117698.1). The NWD1 gene is highly conserved among mammals, with over $70 \%$ nucleotide and amino-acid identities when comparing, for instance, human and murine orthologs. NWD1 was originally annotated as NACHT_P1, and listed as one NACHT domain-containing protein shared by both mammals and fish [21]. The NWD1 protein is phylogenetically clustered with Apaf1 (Apoptotic protease activating factor 1), due to the presence of WD40 repeats instead of LRRs typically found in NLR proteins. NWD1 consists of 1,358 amino acids (GenBank AAI17699.1) and has a calculated molecular mass of 150.84 kilodaltons $(\mathrm{kDa})$. Its protein structure is composed of an N-terminal WD40 repeat, followed by a nucleotide-binding NACHT domain (amino acids 128-454) and then a WD40 repeat-containing region (12 repeats of about 40 amino acids each) at the C-terminus (Fig. 1A).

To access the tissue-specific gene expression profile for NWD1, quantitative PCR analysis was performed using a normalized cDNA panel derived from 48 human tissues (TissueScan Tissue qPCR Array, Origene). Two apparently independent expression patterns were detected, related to neurological organs (brain, pituitary and retina) and male reproductive system (prostate, epididymis and testis), where the highest mRNA levels were observed in prostate tissue (Fig. 1B). Results were confirmed using a second set of NWD1-specific qPCR primers (data not shown). Moreover, a similar expression pattern was virtually observed using the SAGE database from the Cancer 
Genome Anatomy Project (CGAP tag: AGTGACAGAG) of the National Cancer Institute (not shown).

The cellular localization of NWD1 protein was assessed by cell fractionation experiments, using human embryonic kidney (HEK) 293 T cells transfected with a FLAG epitope-tagged NWD1 construct. As shown in Figure 1C, NWD1 was mainly detected in the cytosolic fraction, characterizing it as a potential cytosolic protein, similar to other NLR family proteins.

\section{SRY transcriptional factors are potential activators of $N W D 1$ expression}

To explore potential transcriptional modulators of NWD1 expression, we virtually analyzed the content of high-scoring transcriptional sites located on the putative promoter regions of both human and mouse genes (5 $\mathrm{kb}$ and $4 \mathrm{~kb}$ of genomic 5' regions, respectively), using TFSEARCH $^{\mathrm{TM}}$ [23]. A few transcriptional sites were consistently enriched on both promoter regions (Fig. 2A), particularly SRY sites (sex-determining region $\mathrm{Y}$ ). The SRY transcriptional sites are docking regions for members of the SOX (SRY-related HMG-Box) family of transcription factors, which are largely involved in male sex determination and neuronal development [24, 25]. This observation correlates with the determined pattern of NWD1 gene expression in human tissues (Fig. 1B).

To validate the modulation of NWD1 expression by SRY-related factors, HEK 293T and primary prostatic carcinoma (PPC-1) cell lines were transfected with constructs overexpressing the prototypical SRY (Sexdetermining region $\mathrm{Y}$ protein) or the family counterpart SOX9 (SRY-Related HMG-Box, Gene 9) and then subjected to quantitative PCR analysis. $A R$ over-expression was also analyzed since AR is known to interact with and to be modulated by SRY [26]. In 293T cells, both SRY and $S O X 9$ over-expression induced increases in NWD1 mRNA levels (10- and 13-fold increase, respectively) (Fig. 2B), while less striking increases were stimulated in PPC-1 cells (1.4- and 2.8-fold increase, respectively for SRY and SOX9) (Fig. 2C). The more limited induction of NWD1 expression in PPC-1 cells was possibly due to the lower transfection efficacy when compared to HEK 293T cells. These results suggest that SRY transcription factors positively modulate NWD1 expression. Further studies

A
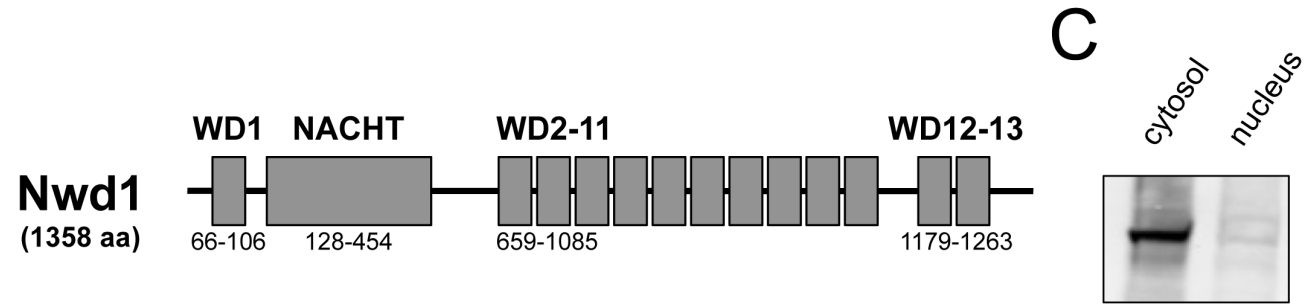

NWD1 (FLAG)
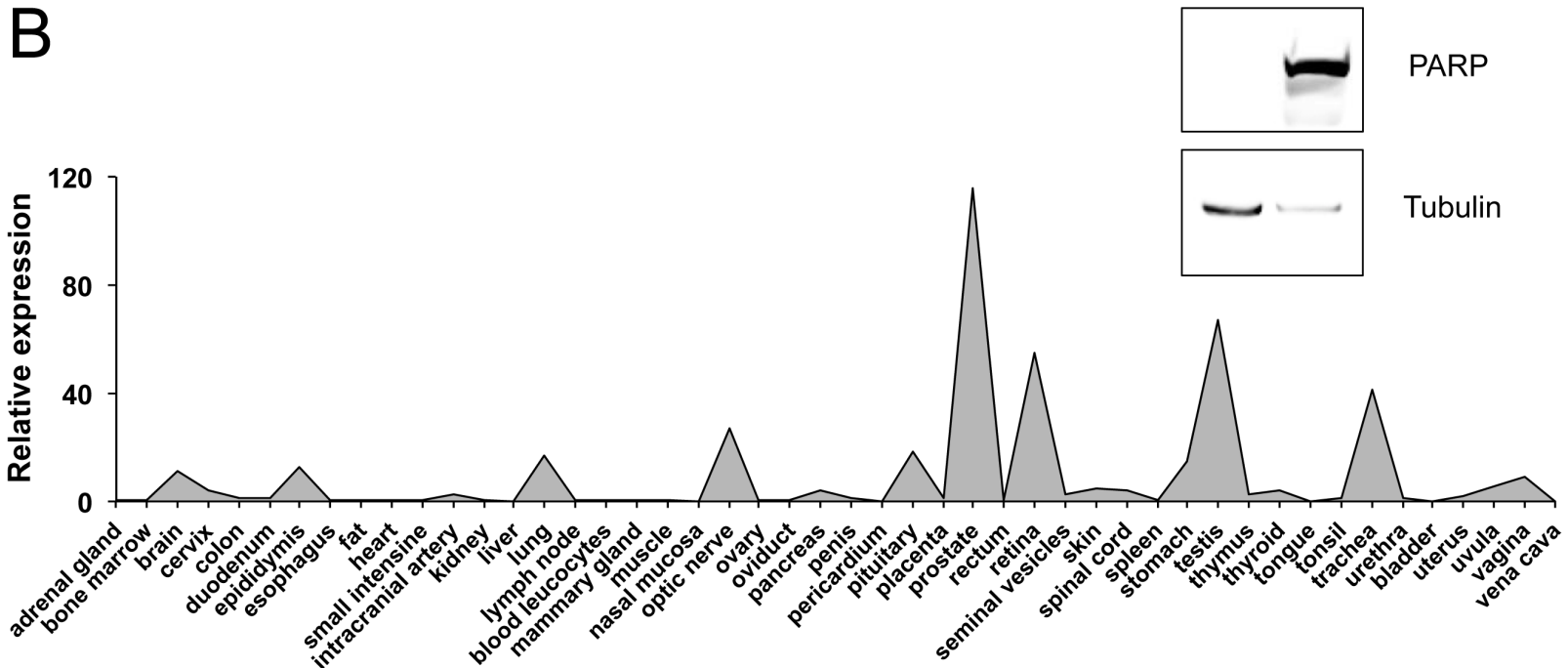

Figure 1: Characterization of NWD1. (A) Domain structure of NWD1. The protein contains a centrally located NACHT region and 13 WD40 repeats (WD1-13). Domain positions are indicated (bottom). (B) Tissue-specific expression of NWD1. A representative graph illustrating the relative NWD1 expression in 48 independent human tissues is shown. First-strand cDNA derived from each tissue sample was normalized according to GAPDH expression (Human Major Tissue qPCR Array, HMRT102, Origene). (C) Subcellular localization of NWD1. HEK 293 T cells cultured in a 10-centimeter plate to $90 \%$ cell confluency were transfected by calcium phosphate with $10 \mu \mathrm{g}$ of FLAG-tagged NWD1 expression vector. After 48 hours, cells were fractionated. A total of $50 \mu \mathrm{g}$ of respective nuclear and cytosolic extract fractions were resolved by SDS-PAGE, and further analyzed by immunoblotting using antibodies specific for $\alpha$-tubulin (cytosolic marker), PARP (nuclear marker) and FLAG-epitope tag (for detection of ectopic NWD1). 
are required to determine whether SRY/SOX9 directly regulate $N W D 1$ expression under physiological conditions.

\section{NWD1 expression is increased in prostate tumorigenesis}

Due to the high NWD1 expression detected in human prostate and its potential modulation by effectors involved in male sex differentiation and proliferation, we surveyed NWD1 expression levels in a subset of prototypical PCa cell lines. The lowest expression levels were detected in the neonatal human prostate epithelial cell line $267 \mathrm{~b} 1$, followed by a modest increase in the androgen-responsive and PSA (prostate-specific antigen)expressing LNCaP and 22Rv1 cells (Fig. 3A). The highest levels of $N W D 1$ expression were observed in the androgen-independent and highly metastatic prostate cell lines PC-3 and PPC-1 (Fig. 3A).
Changes in the levels of NWD1 expression, and its possible correlation with $\mathrm{PCa}$ progression, were further investigated by quantitative PCR analysis using a normalized cDNA panel derived from isolated prostate samples $(n=48)$ at different tumor stages (TissueScan Prostate Cancer Tissue qPCR Panel I, Origene) (Fig. $3 \mathrm{~B})$. An increase in NWD1 expression could be observed, particularly when comparing normal tissues $(n=7)$ versus stage II tumor samples ( $\mathrm{n}=19)$ (Fig. 3B). In fact, stage II tumor samples with assigned Gleason score and reported TNM $(n=7)$ showed an increase of 5 -fold $(\mathrm{p}<0.0001)$ in NWD1 mRNA expression levels when compared to normal prostate tissues (Fig. 3C). An increase of 2.4-fold was also detected in hyperplasic tissues $(\mathrm{BPH})(\mathrm{n}=11)$ but failed to reach statistical significance when compared to normal samples $(p=0.05)$ (Fig. 3C). A relative increase in NWD1 expression at the mRNA level could also be inferred for stage III prostate tumors but due to the limited number of samples tested (also for stages I and IV), no statistical
A

\begin{tabular}{|l|c|c|}
\hline Transcriptional site & $\begin{array}{c}\text { Human NWD1 } \\
\text { (5 kB) }\end{array}$ & $\begin{array}{c}\text { Murine NWD1 } \\
\text { (4 kB) }\end{array}$ \\
\hline $\begin{array}{l}\text { SRY } \\
\text { (male sex determination) }\end{array}$ & 18 & 04 \\
\hline $\begin{array}{l}\text { Nkx-2.1 } \\
\text { (thyroid \& lung } \\
\text { development) }\end{array}$ & 06 & 02 \\
\hline GATA & 03 & 02 \\
\hline AML-1a & 01 & 01 \\
\hline HFH-2 & 01 & 01 \\
\hline $\begin{array}{l}\text { Lyf-1 } \\
\text { (T-and B-cell development) }\end{array}$ & 08 & -- \\
\hline $\begin{array}{l}\text { CdxA } \\
\text { (intestinal specification) }\end{array}$ & 08 & -- \\
\hline Sp1 & 01 & -- \\
\hline c-Ets & 01 & -- \\
\hline deltaE & 01 & -- \\
\hline Sox5 & -- & 02 \\
\hline Oct-1 & -- & 01 \\
\hline v-Myb & -- & 01 \\
\hline Total & $\mathbf{4 8}$ & $\mathbf{1 4}$ \\
\hline
\end{tabular}

$\mathrm{B}$

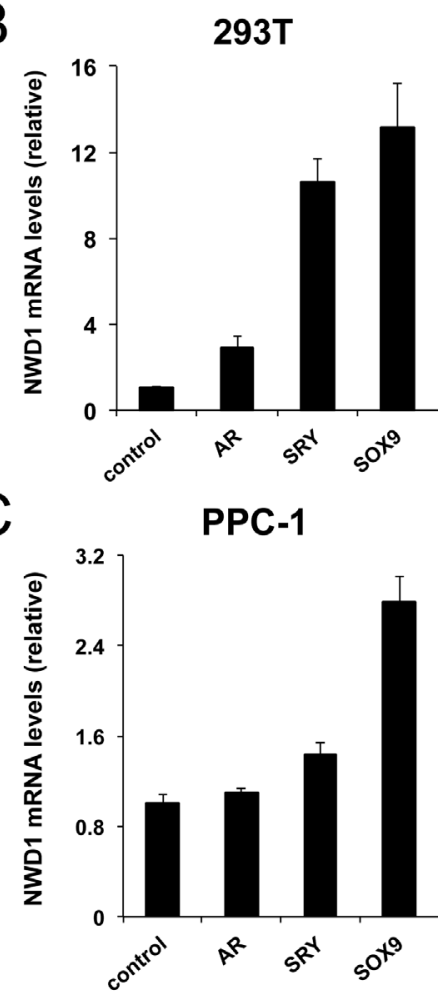

Figure 2: Upstream modulation of NWD1 expression. (A) Table listing predicted transcriptional binding sites (high scoring entries) conserved in murine and human $N W D 1$ promoter regions. Transcriptional sites were annotated using TRANSFAC ${ }^{\mathrm{TM}}$ matrix table with threshold of 95 (TFSEARCH $^{\mathrm{TM}}$ version 1.3). The human and mouse promoter regions were estimated after BLAST analysis of respective genomic sequences (GenBank NC_000019.9, positions 16825787-16830786, and GenBank NC_000074.5, positions 7516664775170613, respectively). The biological relevance of most representative sites is also described. (B) Real-Time PCR analysis of NWD1 mRNA levels in transfected HEK $293 \mathrm{~T}$ cells. Cells in 10-centimeter plates ( $90 \%$ cell confluency) were transfected by calcium phosphate with $10 \mu \mathrm{g}$ of plasmid DNA encoding AR, SRY, SOX9 or EGFP (control). At 36 hours post-transfection, cells were processed for RNA purification and first-strand cDNA synthesis followed by PCR amplification. RNA levels were normalized by cyclophilin (CPH) expression. Relative values (y-axis) were obtained after comparison to expression in control cells (mean value $=1$ ). Values presented are averages of at least three replicates (+ standard deviation). (C) Real-Time PCR analysis of NWD1 mRNA levels in transfected PPC-1 cells. Cells in 10 -centimeter plates ( $90 \%$ cell confluency) were transfected by Fugene HD ${ }^{\mathrm{TM}}$ (Roche) with $2 \mu \mathrm{g}$ of respective DNA plasmids. At 48 hours after transfection, total RNA was isolated for first-strand cDNA synthesis and PCR amplification. RNA levels were normalized by $18 \mathrm{~S}$ ribosomal RNA expression. Values were expressed as in (B). 
A

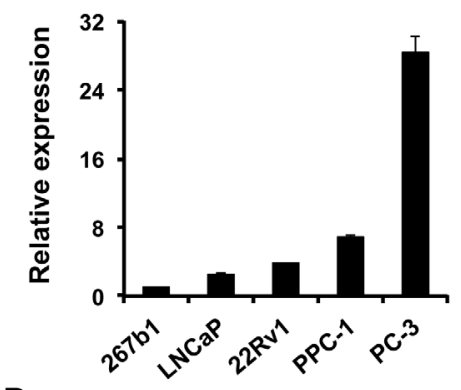

C

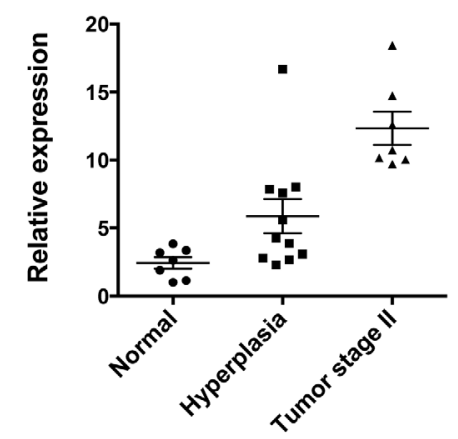

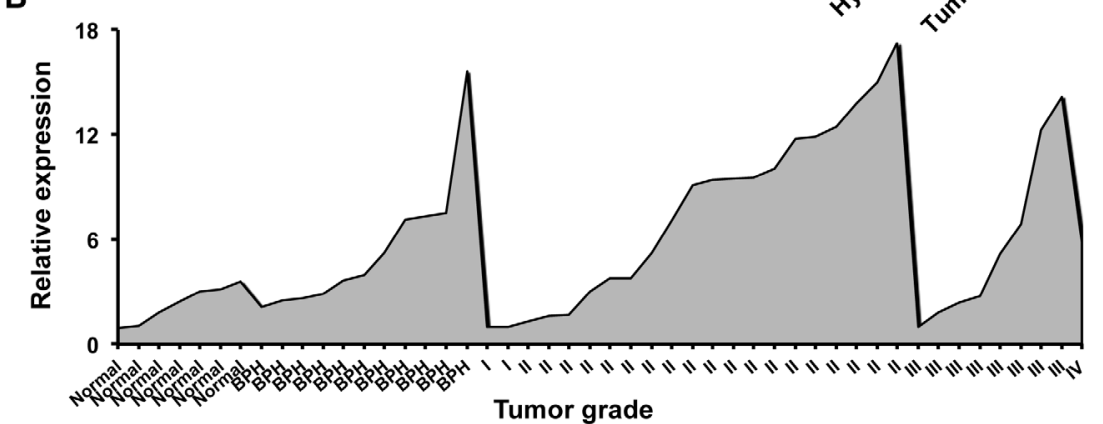
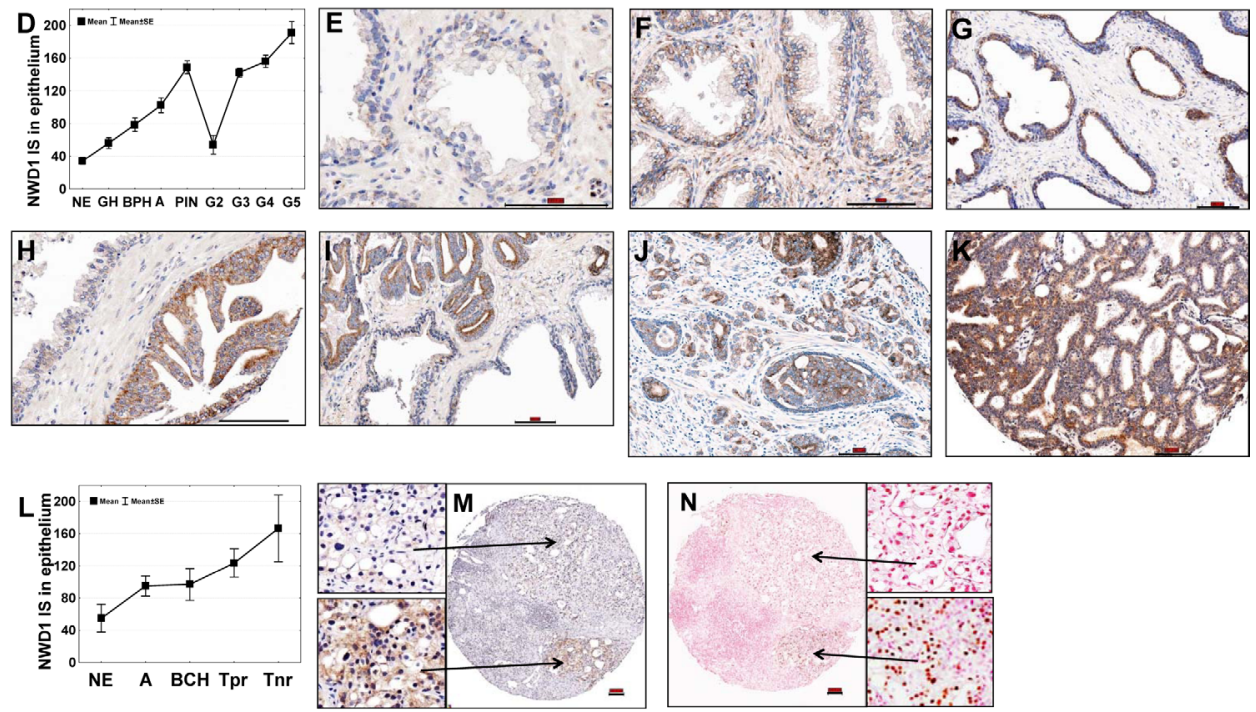

Figure 3: Expression patterns of NWD1 in prostate cancer. (A) Real-Time PCR analysis of NWD1 mRNA levels in a subset of prostate cell lines. RNA levels were normalized by cyclophilin $(\mathrm{CPH})$ expression. Relative values (y-axis) were obtained after comparison to expression in normal prostate $267 \mathrm{~b} 1$ cell line (mean value $=1$ ). The values presented are averages of at least three replicates $(+$ standard deviation). (B) Stage-related expression of NWD1 in prostate cancer. A limited sampling of four disease stages, benign prostate hyperplasia $(\mathrm{BPH})$ and normal tissues was evaluated by Real-Time PCR analysis. A representative graph illustrating the relative NWD1 expression using a pre-normalized cDNA panel, derived from respective tissue samples $(\mathrm{n}=48)$ at different tumor stages (TissueScan Prostate Cancer Tissue qPCR Panel I, HPRT101, Origene), is shown. (C) Comparative expression of NWDl in normal and hyperplasic (BPH) tissues and stage II tumors. Relative values derived from (B) were re-plotted for stage II tumor samples with assigned Gleason score and reported TNM ( $\mathrm{n}=7$ ). (D) NWD1 protein distribution in human prostate specimens. A box and whisker plot depicts NWD1 immunoscore data for normal prostatic epithelium (NE), glandular hyperplasia (GH), BPH, atrophy (A), prostatic intraepithelial neoplasia (PIN), and prostate adenocarcinoma Gleason grade 2-5 (G2-G5). (E-K) TMA sections containing prostate specimens from 109 prostate cancer patients were immunostained for NWD1 using polymer-based EnVision-HRP-enzyme conjugate and DAB chromogen (brown). Representative examples of NWD1 protein expression in the normal prostatic epithelium (E), BPH (F), atrophy $(\mathrm{G})$, PIN $(\mathrm{H})$, and progressing prostate adenocarcinoma (I-K) are provided. Specimens were counterstained with hematoxylin. Bar $\sim 100 \mu \mathrm{m}$. (L) Immunohistochemical detection of NWD1 protein in castration-resistant prostate cancers. A box and whisker plot depicts NWD1 immunoscore data for normal prostatic epithelium (NE), atrophy (A), basal cell hyperplasia (BCH), and prostate cancer with partial (Tpr) or no response (Tnr) to androgen deprivation therapy. (MN) Serial TMA sections containing 66 cores of prostate specimens from 18 prostate cancer patients with partial or no response to androgen deprivation therapy were immunostained for NWD1 $(\mathrm{M})$ and AR $(\mathrm{N})$ using polymer-based EnVision-HRP-enzyme conjugate and DAB chromogen (brown). Specimens were counterstained with hematoxylin (M) and nuclear fast red (N). Bar $\sim 100 \mu \mathrm{m}$. 
difference could be assumed.

To verify the consistency of the RNA expression data with the respective protein yields, we generated polyclonal antibodies against NWD1 to further evaluate protein levels in prostatectomy samples containing tumor tissue representing different Gleason grades. The antibody specificity was validated by testing against other NLR family proteins (Supplementary Fig. 1). In prostate tissue specimens derived from $109 \mathrm{PCa}$ stage T2 and T3 patients, immunohistochemical analysis revealed low expression of NWD1 in normal prostatic epithelium $(\mathrm{n}=39)$, which markedly increased in glandular hyperplasia $(\mathrm{GH} ; \mathrm{n}=28)(p=0.006)$, benign prostatic hyperplasia (BPH; $\mathrm{n}=40)(p<0.0001)$, atrophy (A; $\mathrm{n}=53)(p<0.0001)$, and prostatic intraepithelial neoplasia (PIN; $\mathrm{n}=48)(p<0.0001)$. Although barely expressed in Gleason grade $\mathrm{G} 2$ adenocarcinoma $(\mathrm{n}=11)$, NWD1 was significantly up-regulated in G3 $(\mathrm{n}=166)(p<0.0001)$, $\mathrm{G} 4(\mathrm{n}=68)(p<0.0001)$, and G5 $(\mathrm{n}=8)(p<0.0001)$ PCa specimens compared to the normal prostate glands (Figs. 3 D-K). Increased levels of NWD1 immunostaining were found in samples of prostate tumors resistant to androgen deprivation therapy $(\mathrm{n}=20)$. Specimens with histologic evidence of partial (Tpr; $n=14)$ or no response (Tnr; $\mathrm{n}=6$ ) to pharmacological castration showed significantly elevated NWD1 protein levels compared to the normal prostatic epithelium $(p=0.02)$ (Figs. 3 L-N). High expression of NWD1 (median cut-off) was associated with areas of AR positive immunostaining in $75 \%$ of hormone refractory tumor samples (15/20) (Figs. $3 \mathrm{M}-\mathrm{N}$ ). Altogether, NWD1 can be considered as a potential PCa biomarker, since its increased expression at both RNA and protein levels is associated with malignant progression.

\section{NWD1 activity in androgen-independent prostate cancer cells}

To explore a functional role for NWD1 in $\mathrm{PCa}$ progression, we designed a lentiviral-based gene silencing approach to knockdown NWD1 expression in PPC-1 cells (Supplementary Fig. 2), one of the PCa cell lines with high NWD1 mRNA levels (Fig. 3A). PPC-1 is a highly transfectable variant of PC-3 cells, originally described as a good model system for the study of PCa progression [27]. Under basal conditions, no major changes in cell proliferation or cell migration in vitro (wound healing assay) or tumor development in mouse xenografts (using 7 week-old female nude mice) were noticed when silencing NWD1, using PPC-1 as cellular model (data not shown). Also, PPC-1 cells treated with TRAIL (TNF-Related Apoptosis-Inducing Ligand), separately or in combination with the chemotherapy drug doxorubicin (DOX), were only slightly more sensitive when NWD1 expression was silenced (Fig. 4A). No significant differences were noticed after treatment with the chemotherapy drug Taxol/
Paclitaxel (data not shown).

With respect to affects of NWD1 gene silencing on cytokine signaling, we used a NF- $\kappa B$ dependent luciferase reporter as an assay platform, which is strongly activated by cytokines such as TNF- $\alpha$ and by the chemotherapeutic drug DOX. We observed that NWD1-depleted 293T cells produce higher NF- $\mathrm{\kappa B}$ reporter gene activation after treatment with these inducers when compared to the control cells (Fig. 4B). Importantly, reconstituting NWD1 expression in the shRNA-based depleted cells reduced $\mathrm{NF}-\kappa \mathrm{B}$ activation comparably to control levels (Fig. 4B). In contrast to NF- $\mathrm{kB}$, experiments using an AP-1driven luciferase reporter gene revealed no defect in AP-1 signaling following NWD1 knockdown (Supplementary Fig. 3), thus demonstrating the specificity of our results. These observations indicate that NWD1 expression can affect cell viability and NF- $\mathrm{\kappa B}$ signaling, similar to many NLR family proteins $[18,28]$.

The participation of NWD1 in signaling transduction pathways was further examined by microarray analysis (Human WG-6v3 Expression BeadChip, Illumina), comparing the expression profile of PPC-1 cells lacking $N W D 1$ expression $(\sim 5 \%$ residual expression, Supplementary Fig. 2) versus control cells. According to the differential expression profile that was generated and analyzed by the Ingenuity Pathways ${ }^{\mathrm{TM}}$ software (IPA version 7.1, Ingenuity Systems), NWD1 is presumably associated with biological networks related to tissue morphology, organogenesis, cancer and neurological diseases (Supplementary Figs. 4-5). A list including most of the genes that are more dramatically up or down regulated after NWD1 knockdown is shown (Supplementary Fig. 4). Still, a very limited number of genes was transcriptionally induced or repressed with a difference of $>2$-fold (a total of 13 and 18 genes, respectively).

After validation of several promising hits by quantitative PCR analysis (Fig. 4C), we observed that $P D E F$ was the most quantitatively down-modulated target gene, with approximately 4 -fold reduction $(\sim 75 \%$ suppression). Interestingly, shRNA-mediated silencing of $N W D 1$ expression also reduced $P D E F$ mRNA levels in other human cell lines, including 293T, THP.1 and HeLa-S cells (Fig. 4D), suggesting conservation of NWD1dependence for $P D E F$ expression across cell types.

PDEF is a prostate epithelial-specific Ets transcription factor, which is involved in PSA gene regulation and acts as a co-regulator of AR [29]. Remarkably, PDEF has been described as one of the few transcription factors with potential to have a significant impact on the management of $\mathrm{PCa}$ [30]. Since the expression of $P D E F$ is typically up-regulated following activation of the AR signaling [31,32], we considered that NWD1 might have a more intimate role on this signaling pathway and designed experiments to test this hypothesis. 


\section{NWD1 activity in androgen-responsive prostate cancer cells}

To investigate a potential role for NWD1 in AR signaling in $\mathrm{PCa}$, we stably knocked down expression of NWD1 in androgen-responsive PCa cells LNCaP and 22Rv1. Strikingly, constitutive depletion of NWD1 expression dramatically affected the viability of transduced LNCaP cells, whereas the same depletion marginally affected the proliferation of transduced 22Rv1 cells (Fig. 5A). A consistent decrease in cell viability was observed using two additional lentiviral-based shRNA constructs targeting NWD1 (data not shown). Despite both cells lines being androgen-responsive, androgendependent cell proliferation is only observed for $\mathrm{LNCaP}$ cells. In fact, 22Rv1 cells express two separate AR protein species, where one of them is constitutively nuclear and

A

TRAIL

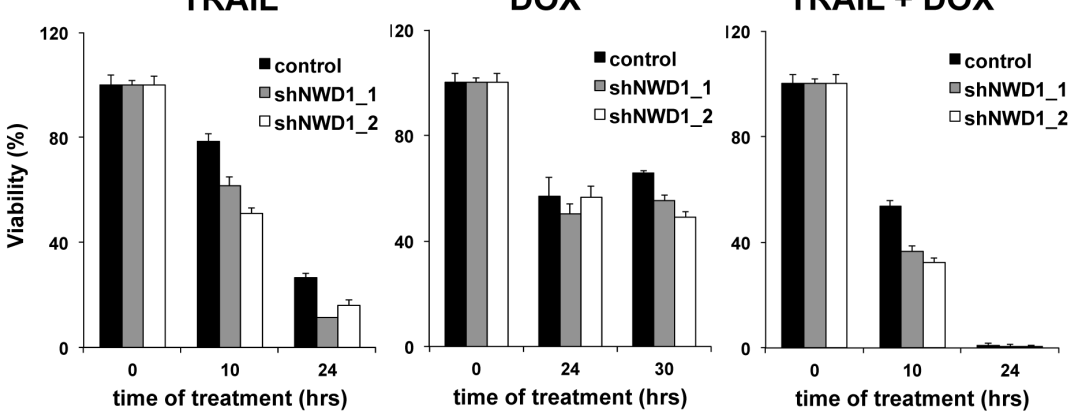

C

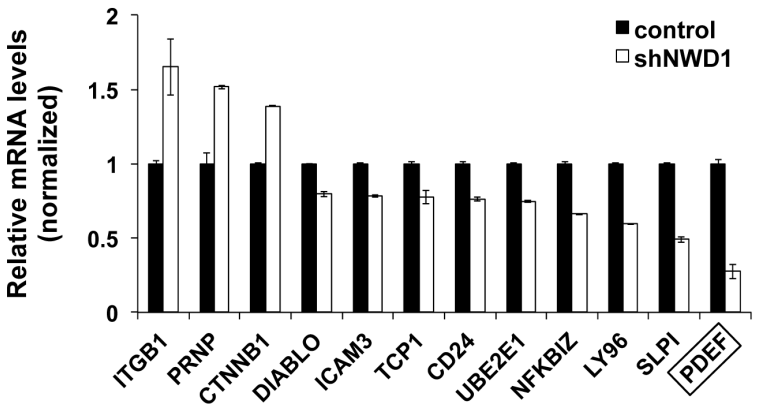

B

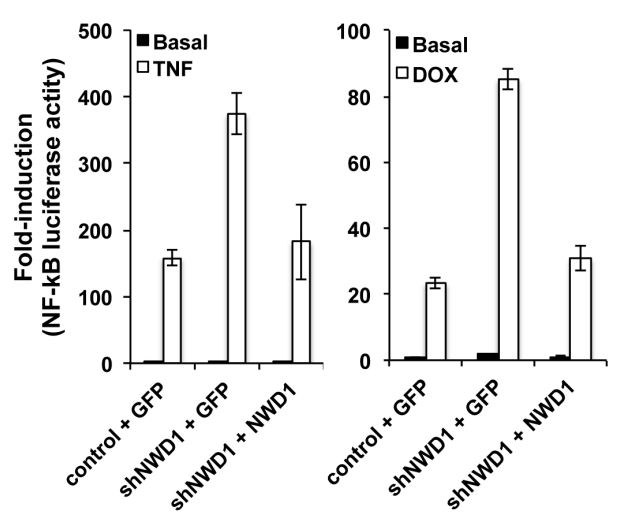

THP.1

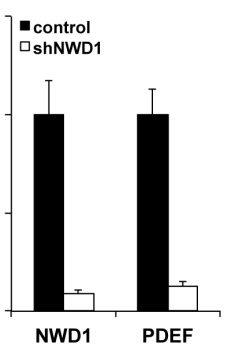

HeLa-S

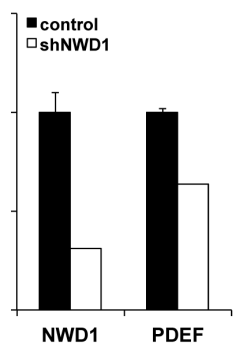

Figure 4: Effects of $N W D 1$ gene silencing in vitro. (A) Cell viability analysis. PPC-1 cells (5x103 cells/well in 96-well plate) constitutively expressing shRNAs against EGFP (control) or NWD1 (shNWD1_1 and shNWD1_2) were respectively treated with 100 ng/ $\mathrm{ml}$ TRAIL, $1 \mu \mathrm{M}$ DOX or their combination for different times (10,24 or 30 hours). Cell viability and growth was determined by performing WST-1 assay (Roche) reading absorbance at $450 \mathrm{~nm}$ (reference wavelength of $690 \mathrm{~nm}$ ) according to the manufacturer's instructions. Values were converted to percentage of viability according to the measurements obtained for non-treated cells (considered as $100 \%$ viable). The values presented are averages of four replicates (+ standard deviation). (B) Activity towards NF- $\kappa$ B signaling pathway. HEK 293T cells

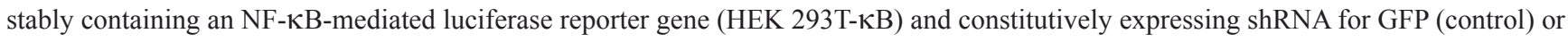
NWD1 (shNWD1) were plated in 10-cm dish and, at 90\% confluency, were transfected by calcium phosphate with $20 \mu \mathrm{g}$ of GFP or NWD1 expression vectors. At 24 hours post-transfection, cells were resuspended and loaded into 96-well plate at 5x104 cells/well. Cells were further treated with $10 \mathrm{ng} / \mathrm{ml} \mathrm{TNF}$ (left graph) or $0.4 \mu \mathrm{g} / \mathrm{ml} \mathrm{DOX} \mathrm{(right} \mathrm{graph)} \mathrm{in} \mathrm{serum-free} \mathrm{medium} \mathrm{for} 18$ hours. Luciferase activity was measured using Steady-Glo ${ }^{\mathrm{TM}}$ reagent (Promega). Values were converted to fold-induction in NF- $\mathrm{KB}$ activity according to the measurement obtained for non-treated (basal) control cells (mean value $=1)$. Values represent averages of three replicates $(+$ standard deviation). $(\mathrm{C})$ Real-Time PCR validation of putative NWD1 target genes identified by microarray analysis. PPC-1 cells constitutively expressing shGFP (control) or shNWD1 were processed for isolation of total RNA and first-strand cDNA synthesis. RNA levels were normalized by $18 \mathrm{~S}$ ribosomal RNA expression. Relative values (y-axis) were obtained by comparison to the expression in control cells (mean value $=1$ ). The values presented are averages of at least three replicates (+ standard deviation). The target gene with highest fold change on expression (PDEF) is indicated. (D) Real-Time PCR validation of PDEF as an NWD1 target gene in different cell lines. HEK 293T, THP.1 and HeLa-S cells constitutively expressing shGFP (control) or shNWD1 were respectively processed for isolation of total RNA and first-strand cDNA synthesis, followed by PCR amplification. RNA levels were normalized by cyclophilin (CPH) expression. Normalized levels of NWD1 expression are also shown. Values were expressed as in (C) 
binds DNA independent of androgens [33], accounting for why its proliferation is less affected by hormone ablation.

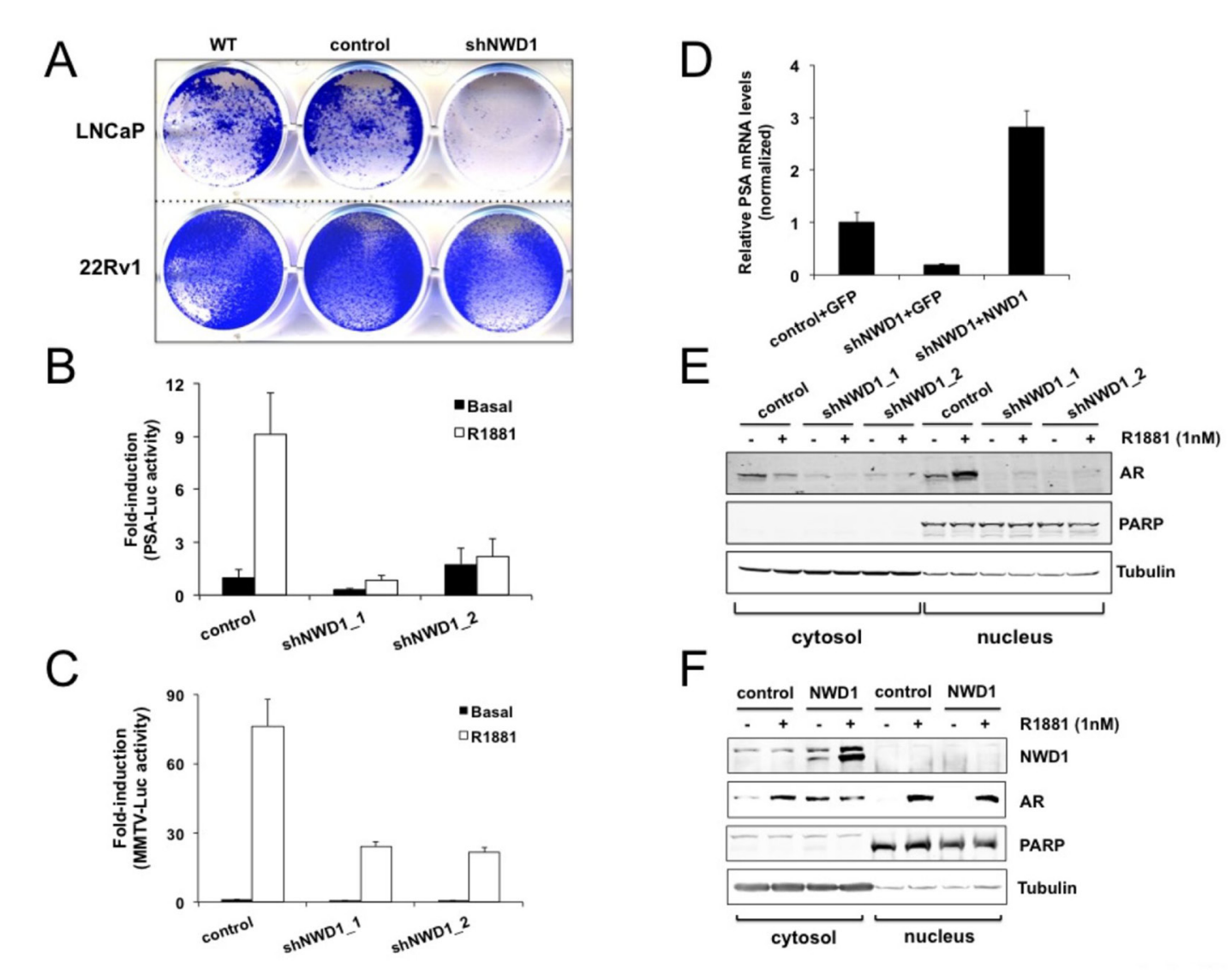

Decreased cell proliferation and reduced cell viability were also observed in NWD1 shRNA-transduced LAPC-

Figure 5: NWD1 participates in androgen receptor (AR) signaling. (A) Viability analysis of androgen-responsive prostate cancer cells (LNCaP and 22Rv1). Cells plated in 6-well dishes at 90\% confluency were infected with lentiviruses (MOI $\geq 100$ ) to constitutively express shGFP (control) or shNWD1. At 48 hours post-infection, cells were transferred to 12 -well dishes (10 viable cells/well) and cultured for an addtional 3-4 days, before fixing cells and staining with crystal violet. Staining of non-infected wild-type (WT) cells was utilized as a standard control. (B) PSA-mediated luciferase reporter assay. LNCaP cells $\left(10^{6}\right.$ cells/well in 6 -well dish) were transfected by GenJet reagent (SignaGen) with $1 \mu \mathrm{g}$ of shGFP (control) or shNWD1 constructs plus $0.7 \mu \mathrm{g}$ PSA-mediated firefly luciferase and 0.3 $\mu \mathrm{g}$ thymidine kinase (TK)-mediated Renilla reporter plasmids per well. After 24 hours of transfection, cells were transferred to 96 -well dish $\left(2 \times 10^{4}\right.$ viable cells/well in charcoal-stripped serum containing medium) and treated or not with $1 \mathrm{nM}$ R1881 for 60 hours. Luciferase activity was measured using Dual-Luciferase ${ }^{\mathrm{TM}}$ Reporter Assay System (Promega). Values were normalized according to Renilla luciferase signals. Values were converted to fold-induction in PSA-mediated activity according to the measurement obtained for non-treated (basal) control cells (mean value $=1$ ). The values presented are averages of three replicates (+ standard deviation). (C) MMTV-mediated luciferase reporter assay. $\mathrm{LNCaP}$ cells were plated in $96-$ well dishes $\left(3 \times 10^{4}\right.$ cells/well in charcoal-stripped serum containing medium) and transfected by JetPrime reagent (PolyPlus) using $0.05 \mu \mathrm{g}$ of respective shRNA constructs, $0.02 \mu \mathrm{g}$ of AR expression vector, $0.02 \mu \mathrm{g}$ MMTV-mediated firefly luciferase and $0.01 \mu \mathrm{g}$ thymidine kinase (TK)-mediated Renilla reporter plasmids per well. After 24 hours of transfection, cells were induced or not with $1 \mathrm{nM}$ R1881 for further 24 hours. Luminescence values were measured and processed as in (B). (D) Real-Time PCR analysis of PSA expression levels. HEK 293 T cells in 10-centimeter plates (90\% cell confluency), constitutively expressing shGFP (control) or shNWD1, were transfected by calcium phosphate with $20 \mu \mathrm{g}$ of DNA constructs to respectively overexpress GFP or NWD1. At 40 hours post-transfection, cells were processed for standard RNA purification and first-strand cDNA synthesis. RNA levels were normalized by cyclophilin $(\mathrm{CPH})$ expression. Relative values (y-axis) were obtained by comparing to the PSA expression in GFP-transfected control cells (mean value $=1$ ). The values presented are averages of at least three replicates (+ standard deviation). (E) Analysis of exogenous AR content and trafficking by subcellular fractionation. PPC-1 cells in 10-centimeter plates ( $90 \%$ confluency) were transfected by JetPrime reagent (PolyPlus) with $6 \mu \mathrm{g}$ of shRNA constructs to knockdown EGFP (control) or NWD1 (shNWD1_1 and shNWD1_2) plus $3 \mu \mathrm{g}$ of AR expression vector. Cells were split 24 hours after transfection and cultured in charcoal-stripped serum containing media for 48 hours. Cells were further treated with (+) or without (-) $1 \mathrm{nM} \mathrm{R} 1881$ for 28 hours. Cytosolic and nuclear subcellular fractions were isolated and analyzed (50 $\mu$ g protein) by immunoblotting using antibodies specific for $\alpha$-tubulin (cytosolic marker), PARP (nuclear marker) and AR. (F) Analysis of endogenous AR content and trafficking by subcellular fractionation. LNCaP cells in 10 -centimeter plates ( $70 \%$ confluency in charcoal-stripped serum containing medium) were transfected by JetPrime reagent (PolyPlus) with $10 \mu \mathrm{g}$ of GFP (control) or FLAG-NWD1 expression constructs. At 48 hours post-transfection, cells were treated with (+) or without (-) 1nM R1881 for 32 hours. Fractionation analysis followed as in (E), including anti-FLAG antibody for exogenous NWD1 detection. 
Table 1:NWD1 interacting proteins identified by proteomic analysis. LNCaP cells in T-75 flasks ( $70 \%$ confluency), cultured in standard RPMI 10\% FBS supplemented with $0.5 \mathrm{nM}$ R1881 (to stimulate cell growth), were transfected by TransIT-2020 reagent (Mirus) with $10 \mu \mathrm{g}$ of FLAG-GFP (control) or FLAG-NWD1 expression constructs. At 96 hours post-transfection, cells were lysed for further immunoprecipitation (IP) procedures using anti-FLAG beads. Mass spectrometry (1D LC-MS/MS) was performed twice using respective IP eluates. Protein hits also present in the control sample were subtracted to point out specific NWD1-related hits. Each protein entry shows the respective IPI (International Protein Index) number and the total protein spectral counts. The respective protein functions are also listed.

\begin{tabular}{|l|l|l|l|l|}
\hline IPI\# & $\begin{array}{l}\text { Gene } \\
\text { Symbol }\end{array}$ & Protein Identified & $\begin{array}{l}\text { Spectral } \\
\text { Count }\end{array}$ & Function \\
\hline IPI00744647 & NWD1 & NACHT and WD repeat domain-containing protein 1 & 401 & \\
\hline IPI00007752 & TUBB2C & Tubulin beta-2C chain & 99 & microtubule structure \\
\hline IPI00941328 & HSPA1B & Heat shock 70kDa protein 1B & 92 & chaperone \\
\hline IPI00382470 & HSP90AA1 & Heat shock protein HSP 90-alpha & 54 & chaperone \\
\hline IPI00414676 & HSP90AB1 & Heat shock protein HSP 90-beta & 50 & chaperone \\
\hline IPI00292496 & TUBB8 & Tubulin beta-8 chain & 42 & microtubule structure \\
\hline IPI00015947 & DNAJB1 & DnaJ (Hsp40) homolog subfamily B member 1 & 22 & co-chaperone \\
\hline IPI00008868 & MAP1B & Microtubule-associated protein 1B & 21 & microtubule assembly \\
\hline IPI00000643 & BAG2 & BAG family molecular chaperone regulator 2 & 11 & co-chaperone \\
\hline IPI00480014 & SSX11 & Synovial sarcoma X (SSX) breakpoint protein 11 & 10 & $\begin{array}{l}\text { transcriptional } \\
\text { modulation }\end{array}$ \\
\hline IPI00030275 & TRAP1 & Heat shock protein 75 kDa, mitochondrial & 8 & chaperone \\
\hline IPI00000690 & AIFM1 & Apoptosis-inducing factor 1, mitochondrial & 7 & regulation of apoptosis \\
\hline IPI00020058 & ATP7B & Copper-transporting ATPase 2 & 4 & copper transport \\
\hline IPI00554648 & KRT8 & Keratin, type II cytoskeletal 8 & 4 & cytoskeleton structure \\
\hline IPI00015842 & RCN1 & Reticulocalbin-1 & 3 & calcium binding \\
\hline IPI00021187 & RUVBL1 & RuvB-like 1 & 3 & $\begin{array}{l}\text { transcriptional } \\
\text { modulation }\end{array}$ \\
\hline IPI00029628 & RCN2 & Reticulocalbin-2 & 3 & calcium binding \\
\hline IPI00064328 & PRMT5 & Protein arginine N-methyltransferase 5 & 3 & metabolic modulation \\
\hline IPI00440493 & ATP5A1 & ATP synthase subunit alpha, mitochondrial & 3 & ATP synthesis \\
\hline IPI00032406 & DNAJA2 & DnaJ (Hsp40) homolog subfamily A member 2 & 2 & co-chaperone \\
\hline IPI00909055 & KLHDC3 & Kelch domain-containing protein 3 & 2 & meiotic recombination \\
\hline
\end{tabular}

4 cells, another androgen-responsive cell model (data not shown). These observations suggest that NWD1 could be important for AR activity and/or downstream ARmediated signaling events in androgen-dependent PCa cells.

To evaluate whether NWD1 depletion could modulate AR signaling in androgen-dependent prostate cells, we transiently knocked down NWD1 expression in $\mathrm{LNCaP}$ cells and then performed reporter gene assays to monitor effects on either the PSA or MMTV promoters, both known to be activated by androgens (Figs. 5 B-C). Under basal conditions, no major differences were noticed regarding PSA- or MMTV-mediated luciferase reporter gene activity. In contrast, androgen-dependent luciferase activity induced by treatment with the synthetic androgen R1881 was consistently attenuated by shRNA-mediated silencing of $N W D 1$ expression. PSA-dependent luciferase activity in androgen-treated cells was reduced by 76 to
91\% after NWD1 silencing (using two independent shRNA constructs) (Fig. 5B). Similarly, MMTVdependent luciferase activity in androgen-treated cells was diminished by approximately $70 \%$ as a result of $N W D 1$ gene silencing (Fig. 5C). In contrast to gene knockdown, NWD1 over-expression did not lead to major changes in PSA- or MMTV-mediated luciferase activities (data not shown). Based on these results, we conclude that NWD1 potentially participates in AR signaling, since its depletion negatively affects androgen responsiveness towards the activation of AR-responsive reporter genes.

Next, we evaluated the impact of stable and constitutive NWD1 gene silencing on expression of the endogenous PSA gene, a prototypical AR target gene [34]. Previously, it has been reported that HEK cells can recapitulate AR biochemical activity [35], thus providing a convenient context for undertaking expression studies. PSA mRNA levels were substantially decreased in NWD1- 
depleted HEK 293T cells, showing approximately 5-fold reduction in PSA expression when compared to control cells (Fig. 5D). Reconstitution of these deficient cells by NWD1 over-expression restored PSA transcript levels that, in fact, resulted in an increase of approximately 3-fold over control cells (Fig. 5D). This result confirms NWD1's role in modulating $P S A$ expression, despite the fact that $A R$ is rarely expressed in $293 \mathrm{~T}$ cells.

The activity of AR is impacted by multiple mechanisms, including regulation of protein stability, cellular trafficking (cytosol-nuclear translocation), post-translational modifications, and interactions with co-activators, co-repressors, and various chromatinmodifying proteins $[36,37]$. To preliminarily probe the mechanisms by which NWD1 modulates AR activity, we assessed the impact of NWD1 knockdown on AR protein levels in PCa cells, obtaining evidence of a decrease in AR levels in NWD1-deficient cells. For example, in experiments using AR-overexpressing PPC-1 cells, NWD1 knockdown was associated with reduced ectopic levels of both cytosolic and nuclear AR protein, both in the presence and absence of the AR agonist R1881 (Fig. 5E). In addition, endogenous AR levels were also decreased in 22Rv1 prostate cells stably expressing NWD1 shRNA (Supplementary Fig. 6A). This decrease in AR protein is not due to ubiquitination and proteasomal degradation, since treatment of cells with the proteasome inhibitor MG132 does not restore AR protein levels (Supplementary Figs. 6A-B). In fact, in accordance with literature reports [37], proteasome inhibition was associated with reduced AR protein expression (e.g., a dramatic decrease of AR endogenous levels was observed in $22 \mathrm{Rv} 1$ cells while no

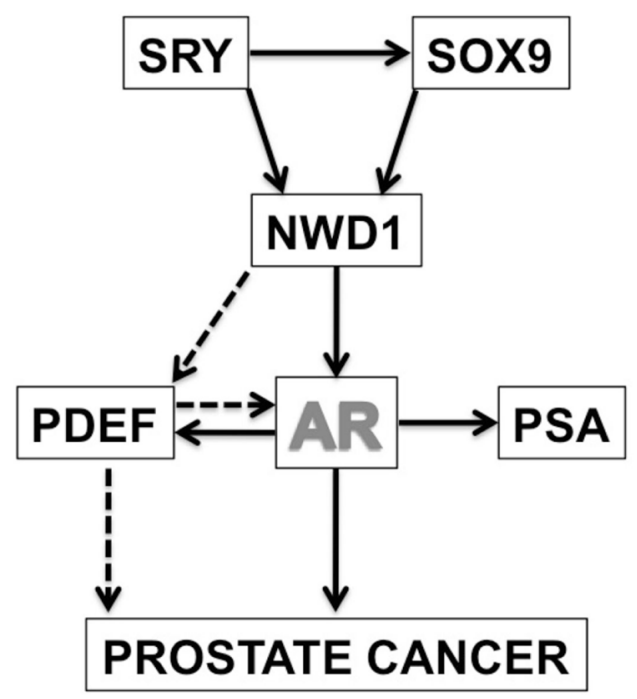

Figure 6: NWD1-dependent AR signaling. Model depicting the participation of NWD1 in AR signaling and its putative correlation with prostate cancer progression. Dashed arrows indicate sub-pathways that require further investigation. major effect was observed on the ectopic levels of ARoverexpressing PPC-1 cells [Supplementary Fig. 6]).

While NWD1 knockdown caused a reduction in AR protein levels, conversely, NWD1 over-expression increased AR endogenous levels in PCa cells. In LNCaP cells, NWD1 over-expression resulted in higher AR basal levels in the cytosol compared to control, when cells were cultured without androgens (Fig. 5F). No apparent changes in the levels of AR translocated to the nucleus were observed after NWD1 over-expression (Fig. 5F) This direct correlation between NWD1 and AR protein levels is consistent with our observations in PCa tumor samples (Figs. $3 \mathrm{M}-\mathrm{N}$ ). We conclude therefore that NWD1 controls steady-state levels of AR. We presume that this accounts at least in part for the ability of NWD1 to modulate AR bioactivity, but cannot exclude the possibility of additional causes such as an impact on AR subcellular trafficking, post-translational modifications, or association with chromatin-modifying proteins.

To gain additional insights into the mechanisms by which NWD1 may modulate AR activity, we sought to identify NWD1 interacting proteins. To this end, we performed LC-MS/MS proteomic analysis of FLAGtagged NWD1 immunoprecipitates (IPs) isolated, at high stringency, from androgen-stimulated LNCaP cells. After subtractive analysis, using FLAG-tagged EGFP IPs as a control, a limited number of interacting proteins were identified, which included chaperone-related proteins such as Hsp90, Hsp40, Bag-2, TRAP1/Hsp75 and HSPA1B (Table 1). Some of these interacting molecules, including Hsp90 and Bag-2, were validated by independent immunoprecipitation assays (Supplementary Fig. 7). Since no evidence of direct binding between NWD1 and endogenous AR was obtained (data not shown), we hypothesize that NWD1 could affect AR activity through the interaction with chaperone complexes.

\section{DISCUSSION}

Here we characterize NWD1 as a newfound NLRrelated protein that contains a central NACHT domain akin to classical NLR family members but that lacks the LRRs required for formal membership in the NLR family. In contrast to mammals, a large number of "atypical" NLRs, containing altered domain organizations have been described in cnidarians [39] and fish [21, 38, 40]. To our knowledge, NWD1 is a unique variant among the NLR members found in humans, since it contains the NACHT domain in the absence of accompanying LRRs. NWD1 possesses WD40 repeats flanking the central NACHT domain, and thus it resembles to some extent the proapoptotic protein Apaf1. The LRR regions of NLRs have a seminal role in pathogen sensing, whereas the WD40 repeats are generally known to be involved in intracellular protein-protein interactions. For example, the WD40 repeat region of Apaf1 promotes binding to cytochrome 
c to trigger formation of the apoptosome and thus initiate caspase activation leading to apoptosis [41].

The human NWD1 gene is located on chromosome $19 \mathrm{p} 13.11$, a genomic region that has shown susceptibility to genomic alterations in hormone-related cancers (ovarian, breast and prostate) [42-45]. In fact, among eighteen loci associated with more than one hormonerelated cancer, this region was particularly identified as a breast and ovarian cancer susceptibility locus by the COGS (Collaborative Oncological Gene-environment Study) consortium [43-45]. Other pathological conditions, including CNS diseases such as ASD (autism spectrum disorder) [46] and pontocerebellar hypoplasias (PCHs) [47], have shown copy number variations and de novo deletions linked to the $19 \mathrm{p} 13.11$ locus, suggesting that this region might contain genes that could be important for CNS development. Interestingly, though not as prominent as male sex hormone-dependent tissues, we found that tissues such as brain, pituitary, optic nerve and retina were among those with higher NWD1 expression.

Expression analysis along a variety of human tissues indicate that male reproductive organs including epididymis, testis and particularly prostate, represent the organs with the highest NWD1 mRNA levels. Interestingly, the expression of some NLR family members, including NLRP2, -3 and -10 , was previously detected at high levels in reproductive organs [48]. Indeed, mutations in the NLR gene $N L R P 7$ has been described as a causative hallmark for recurrent hydatidiform moles (RHM) and reproductive loss [49].

A potential correlation of NWD1 with prostate development was also inferred based on prediction of tissue-specific transcriptional factors that potentially bind within the putative promoter region of the NWD1 gene. In this regard, inspection of the suspected promoter regions of both human and mouse orthologous genes indicated that the most represented potential cis-regulatory sites were consensus DNA binding sites for SRY/SOX9. SRY is a testis-expressed protein that functions as a high mobility group (HMG) box transcription factor and is encoded by the sex-determining region on the $\mathrm{Y}$ chromosome that mediates male sex determination in mammals [50]. Translocations of SRY into the $\mathrm{X}$ chromosome (during paternal meiosis) cause $\mathrm{XX}$ individuals to be male, and loss of function mutations of $S R Y$ cause $\mathrm{XY}$ individuals to be female [24]. SRY expression has also been reported in prostatic tissues, and loss of $S R Y$ and other Y-chromosome-encoded genes is a frequent finding in prostate cancer [51-53]. The genes downstream of SRY involved in sex determination are encoded by autosomes, including the major target sex-determining region $\mathrm{Y}$ box 9 (SOX9). SRY binds to multiple gonad-specific enhancer elements of the $S O X 9$ promoter to up-regulate its expression [50]. High levels of SOX9 have been reported to modulate epithelial cell proliferation within the prostate gland and to cooperate with mutations such as PTEN loss to accelerate prostate neoplasia [54]. In our studies, both $S R Y$ and $S O X 9$ over-expression were able to induce NWD1 expression in vitro, consistent with the presence of predicted binding sites for these transcription factors in the NWD1 gene. However, further studies are required to determine whether SRY and SOX9 directly regulate expression of NWD1 under physiological conditions.

We discovered that both mRNA and protein levels of NWD1 are elevated during prostate cancer pathogenesis or progression. For example, mRNA analysis showed an increase of over 5-fold in NWD1 expression in stage II prostate cancers compared to normal prostatic glandular epithelium. Upregulation of NWD1 was also observed in some cases of BPH and in PIN lesions, suggesting that altered expression can occur in non-malignant hyperplastic and pre-malignant conditions affecting the prostate glands. Interestingly, NWD1 protein as assessed by immunostaining was strikingly higher in histologically more advanced primary PCa tumors (Gleason grade 3-5 versus Gleason 2). Also, in locally advanced PCa tumors, NWD1 immunostaining was higher in primary tumors that failed to achieve pathological complete response (pCR) to anti-androgen treatment in the neoadjuvant setting $[55,56]$. If confirmed in independent patient cohorts, assessment of NWD1 expression levels may provide a biomarker for predicting patient prognosis in some clinical contexts.

While experimental manipulation of NWD1 expression in $\mathrm{PCa}$ and other types of tumor cell lines had some modest effects on NF- $\mathrm{BB}$ activity and cellular sensitivity to cytotoxic cytokines and DNA-damaging anticancer drugs, the most striking cellular phenotype that we uncovered for NWD1 was the profound dependence of LNCaP cells on NWD1 for their growth and survival in culture. $\mathrm{LNCaP}$ are the most androgen-dependent of the available PCa cell lines, which may explain why they were particularly sensitive to loss of NWD1. Consistent with this hypothesis, we determined that NWD1 modulates steady-state levels of AR in PCa cells, possibly by affecting AR protein stability. A positive correlation between NWD1 and AR protein levels was confirmed both in vivo and in vitro. Consistent with the requirement for NWD1 for maintaining AR protein levels, we also determined that NWD1 depletion negatively modulates $P S A$ expression (an endogenous AR-responsive gene) and significantly decreases androgen-dependent induction of AR-responsive reporter genes (driven by PSA and MMTV promoters).

An additional cellular function for NWD1 was uncovered by transcriptome profiling, using PPC-1 cells in which NWD1 expression was silenced. In this regard, we determined that expression of Prostate-derived Ets factor (PDEF) is NWD1-dependent in all human cell lines here tested. Ets transcription factors play an important role in a number of cellular processes including regulation of cell differentiation, proliferation, angiogenesis, and apoptosis. 
PDEF was originally described as an mRNA transcript highly expressed in prostate tumor cells where it regulates PSA expression, acting as an AR co-regulator [30]. In fact, the first PDEF binding partner reported was AR. However, some contradiction is found in the literature regarding the role of $\mathrm{PDEF}$ in $\mathrm{PCa}$, where some groups have reported loss of PDEF during tumor progression [57, 58], while others showed increased expression of PDEF in PCa in comparison to BPH and PIN [31]. Still, PDEF expression is reportedly induced via the AR pathway [30]. Moreover, $\mathrm{Nkx} 3.1$, a prostate tumor suppressor that is frequently lost in PCa, is also a PDEF inhibitor [59], which would be more consistent with an oncogenic role for PDEF in $\mathrm{PCa}$.

The dependence of PDEF expression on NWD1 in a variety of tumor cell lines therefore suggests another connection of NWD1 to AR signaling pathways. How precisely NWD1 exerts its effects on AR and PDEF remains to be determined, but our proteomic analysis of NWD1-interacting proteins suggests an association with molecular chaperone-containing protein complexes. In this regard, molecular chaperones are seminal players throughout the life cycle of AR, since they are known to bind $\mathrm{AR}$ and to modulate its folding, activation, trafficking, and transcriptional activity [60]. Also, the domain structure of NWD1 suggests that this protein could act as a scaffold and/or co-chaperone molecule, in as much as WD40 repeats facilitate protein-protein interactions and thereby coordinate multi-protein complex assemblies [61]. Therefore, NWD1 presumably exerts its effect in the cytoplasm where we found this protein to be predominantly localized. Thus, the site of action of NWD1 may be manifested at times when AR and other unknown NWD1 target proteins are in the cytosol.

In conclusion, based on the data available thus far, we hypothesize a signaling mechanism (Fig. 6) whereby NWD1 acts downstream of SRY family transcription factors to modulate AR activity by stabilizing AR protein levels and by promoting expression of the AR co-activator PDEF in prostate cells. These events would be anticipated to culminate in higher levels of AR activity and thereby aid prostate cell proliferation, growth, and survival. A better understanding of the molecular and cellular properties of NWD1 and the mechanisms by which it modulates AR signaling, as well as the complete framework of NWD1-interacting proteins, merit further investigation to strengthen potential applications of NWD1 as a possible biomarker or therapeutic target for PCa. Indeed, with regards to therapeutic opportunities, the nucleotidebinding NACHT domain of NWD1 theoretically may provide opportunities for small molecule drug discovery based on searches for compounds that displace directly or allosterically nucleotides, which are cofactors required for oligomerization and activation of other NLR family proteins $[62,63]$.

\section{MATERIALS AND METHODS}

\section{Cell lines, reagents and antibodies}

Human embryonic kidney (HEK) 293T and cervical carcinoma HeLa-S cell lines were maintained in Dulbecco modified Eagle medium (DMEM) (CellGro, Mediatech) supplemented with $10 \%$ heat-inactivated fetal bovine serum (Hyclone, Thermo Scientific) and 1\% antibiotic/ antimycotic solution (Omega Scientific) at $37^{\circ} \mathrm{C}$ in an atmosphere of $10 \%$ and $5 \% \mathrm{CO}_{2}$, respectively. All prostate cell lines and THP.1 monocytic cells were cultured in RPMI 1640 medium (CellGro, Mediatech) with the same supplements, at $37^{\circ} \mathrm{C}$ in an atmosphere of $5 \% \mathrm{CO}_{2}$.

The transfection reagents Fugene $\mathrm{HD}^{\mathrm{TM}}$ (Roche Applied Science), GenJet ${ }^{\mathrm{TM}}$ (SignaGen Laboratories), JetPrime $^{\mathrm{TM}}$ (Polyplus Transfection) and TransIT-2020 (Mirus Bio) were acquired from the manufacturers. The synthetic androgen R1881 (methyltrienolone), doxorubicin, taxol (paclitaxel) and TNF- $\alpha$ were obtained from Sigma-Aldrich, and TRAIL was from Calbiochem (EMD Chemicals).

The rabbit anti-NWD1 (585) antibody was raised by immunization with specific antigenic peptide (N-LITLPLVGKPLNLDRKVAPQ-C) (Lampire Biological Laboratories). The rabbit anti-AR (N-20) and mouse anti-ubiquitin (P4D1) antibodies were purchased from Santa Cruz Biotechnology. Mouse anti-FLAG affinity gel (catalog no. A2220-5ML), anti-FLAG (catalog no. F3165), anti- $\beta$-actin (catalog no. A5441) and anti- $\alpha-$ tubulin (catalog no. T9026) antibodies were purchased from Sigma-Aldrich. Rabbit anti-PARP (catalog no. 9542) antibody was from Cell Signaling Technology. The IRDye $^{\mathrm{TM}}$ secondary antibodies were purchased from LICOR Biosciences.

\section{Cloning and lentivirus production}

The human $N W D 1$ open reading frame (ORF) was isolated by RT-PCR (Expand High Fidelity PCR System, Roche) from a pooled cDNA library derived from several organs (fetal brain and kidney, testis, placenta, prostate and breast). Gene-specific primers were designed based on its predicted cDNA sequence (GenBank BC117698.1). The FLAG-tagged NWD1 cDNA was generated after cloning into pcDNA3-Flag plasmid (provided by Shu-ichi Matsuzawa, SBMRI, CA, USA).

For the generation of shRNA-expressing constructs and lentiviral particles, single 83-mer oligonucleotides were designed, containing an $\mathrm{XbaI}$ site at the 5' end and sense and antisense shRNA strands intermediated by a short spacer, plus a partial sequence of the H1RNA promoter at the 3' end. Standard PCR procedures (Advantage 2 PCR kit, Clontech) were performed using 
specific shRNA oligonucleotides and T3 primer plus pSuper-like plasmid [64] as a template to provide H1 promoter driven shRNA cassettes with an additional XbaI site at the 3' end. PCR products were purified (Qiagen), digested with XbaI, and cloned into the 3' LTR NheI site of a CMV-GFP lentiviral vector as described (1). The LV-shGFP construct (control) was kindly donated by Oded Singer (Salk Institute, CA, USA). The following shRNA oligonucleotides were used: 5'CTGTCTAGACAAAAAACACATCCTTGAAGACTGC TCTCTTGAAGCAGTCTTCAAGGATGTGTGGG GATCTGTGGTCTCATACA-3' for shNWD1_1; and 5'- CTGTCTAGACAAAAAGGATGACAAGTATGT GTACTCTCTTGAAGTACACATACTTGTCATCCG GGGATCTGTGGTCTCATACA -3'for shNWD1_2. Vesicular stomatitis virus $\mathrm{G}$ envelope protein-pseudotyped lentiviruses were prepared and purified as described [65].

\section{RNA analysis}

Total RNA was extracted using RNeasy ${ }^{\mathrm{TM}}$ Plus Mini kit (Qiagen). After isolation, 1-5 $\mu \mathrm{g}$ total RNA was reverse-transcribed, in the presence of oligo(dT) primer, according to the manufacturer (SuperScript First-Strand Synthesis, Invitrogen). First-strand cDNA was diluted and analyzed in triplicate with gene-specific primers by real-time PCR, using a Stratagene Mx3000p sequence detection system with SYBR Green PCR master mix (Applied Biosystems). Gene expression data (fold induction) were normalized with the respective levels of $18 \mathrm{~S}$ ribosomal RNA or cyclophilin (CPH) mRNA. The Human Major Tissue qPCR Array (HMRT102) and the TissueScan Prostate Cancer Tissue qPCR Panel I (HPRT101) were normalized by the manufacturer (Origene Technologies, Inc.) and quantitatively screened using specific primers for human NWD1 (forward: 5'-CAATGTGCTTGCTTCTCCAA-3'; reverse: 5'-CTGGTGGTTGGGATGATTCT-3'). Additional primer sequences are available upon request.

For gene expression microarray analysis, labeled cRNA was prepared from $500 \mathrm{ng}$ RNA using the Illumina $^{\mathrm{TM}}$ RNA Amplification Kit (Ambion). The labeled cRNA (1500 ng) was hybridized overnight at $58^{\circ} \mathrm{C}$ to the Sentrix ${ }^{\mathrm{TM}}$ HumanWG-6 Expression BeadChip (>46,000 gene transcripts; Illumina) according to the manufacturer's instructions. BeadChips were subsequently washed and developed with fluorolink streptavidin- Cy3 (GE Healthcare). BeadChips were scanned with an Illumina ${ }^{\mathrm{TM}}$ BeadArray Reader. The generated data was acquired and analyzed using the BeadStudio (Illumina) and Ingenuity IPA $^{\mathrm{TM}}$ software (Ingenuity Systems). All microarray data has been deposited in GEO (accession number GSE53115).

\section{Immunohistochemistry}

Prostate cancer tissue microarrays (TMAs) were constructed as described [66]. An IRB-approved protocol was used to retrieve archival paraffin blocks from the Department of Urology, University of California, Irvine, USA for the UCI NCI SPECS consortium [67]. The TMAs included transurethral resection of the prostate (TURP) and radical prostatectomy specimens from 109 patients with locally confined (stage T2) and locally advanced disease (stage T3). In addition, 34 selected blocks were derived under IRB approval from Department of Pathology, University of California, San Diego, representing tumors from 18 prostatectomy specimens from patients who received preoperative hormone treatment and whose specimens showed histologic evidence of either no or partial response, suggesting hormone refractoriness. The tumor specimens were organized in the TMA format.

Dewaxed tissue sections were immunostained as reported previously [68] using rabbit polyclonal antibodies to AR and NWD1. Application of the primary antibody was followed by incubation with goat antirabbit polymer-based EnVision-HRP-enzyme conjugate (Dako Cytomation). DAB chromogen (Dako Cytomation) was applied, yielding brown color. The TMA slides were scanned at an absolute magnification of $400 \mathrm{x}$ [resolution of $0.25 \mathrm{~mm} / \mathrm{pixel}$ (100,000 pix/in.)] using the Aperio ScanScope CS1 (Aperio Technologies). The acquired digital images were evaluated for NWD1 and AR immunopositivity. The NWD1 immunostaining results were arbitrarily scored according to intensity as 0 , negative; $1+$, weak; $2+$, moderate; or $3+$, strong. The scoring was based on the percentage of immunopositive cells ( 0 to 100$)$ multiplied by staining intensity score $(0 / 1 / 2 / 3)$, yielding scores of 0 to 300 . Data were analyzed using the STATISTICA software package (StatSoft). A one-way analysis of variance (ANOVA) method was used to determine the significance of differences in the NWD1 protein distribution among the different histological categories, and among the cancers with different Gleason grades, or those partially responding or not responding to anti-androgen therapy.

\section{Cell viability assays}

Cells in 96-well plates were analyzed for mitochondrial dehydrogenase activity (as a means of cell proliferation/viability status) using the WST-1 assay according to the manufacturer's protocol (Roche). In brief, $10 \mu \mathrm{L}$ of WST-1 reagent was added to $100 \mu \mathrm{L}$ of cell medium and incubated for $1-2 \mathrm{~h}$ at room temperature. The formazan dye formed was measured at $450 \mathrm{~nm}$ and $690 \mathrm{~nm}$ (background) using a FlexStation 3 Microplate Reader (Molecular Devices).

Cell viability was microscopically assessed after 
crystal violet staining. Briefly, culture dishes were washed three times with phosphate-buffered saline (PBS), and remaining adherent cells were fixed and stained with $0.1 \%$ crystal violet solution in $20 \%$ methanol.

\section{Protein analysis}

For immunoprecipitation (IP) applications, cells were lysed with IP buffer (20 mM HEPES [pH 7.5], 150 $\mathrm{mM} \mathrm{NaCl}, 5 \mathrm{mM} \mathrm{MgCl}, 2$ mM EDTA 1\% NP-40, 10\% glycerol) supplemented with $1 \mathrm{mM}$ dithiothreitol (DTT) and protease inhibitor cocktail (Roche). Equal amounts of clarified protein lysates (2-4 mg) were incubated with 20 $30 \mu 1$ of anti-FLAG ${ }^{\mathrm{TM}} \mathrm{M} 2$ affinity gel (Sigma), in $1 \mathrm{ml}$ of IP buffer for 12 to 16 hours at $4^{\circ} \mathrm{C}$. Immunoprecipitates were washed three times with same buffer, one last wash with TBS buffer (20 mM Tris- $\mathrm{HCl} \mathrm{pH} 7.5,150 \mathrm{mM} \mathrm{NaCl})$ and eluted with $0.5 \mathrm{mg} / \mathrm{ml} \mathrm{FLAG-tag} \mathrm{peptide} \mathrm{(Sigma)} \mathrm{in}$ TBS buffer.

For sub-cellular fractionation, cytosolic fractions were obtained by extensive resuspension of cell pellets into buffer A (10 mM Hepes 7.5, $1.5 \mathrm{mM} \mathrm{MgCl}, 10 \mathrm{mM}$ $\mathrm{KCl}, 0.5 \mathrm{mM}$ DTT and protease inhibitors). The remaining pellet was extensively resuspended into buffer C (20 $\mathrm{mM}$ Hepes 7.5, 25\% glycerol, $450 \mathrm{mM} \mathrm{NaCl}, 1.5 \mathrm{mM}$ $\mathrm{MgCl}_{2}, 0.2 \mathrm{mM}$ EDTA and protease inhibitors) to isolate the nuclear sub-fraction. Total lysates and subcellular fractions were quantified before SDS-PAGE procedures (Bio-Rad Protein Assay). Immunoblotting was performed using various antibodies.

\section{Reporter gene assays}

For reporter gene assays, cells were transduced with a lentiviral vector to introduce $5 \times \kappa \mathrm{B}$-driven luciferase reporter gene or transfected with PSA- or MMTVmediated luciferase reporter gene, TK-mediated Renilla plasmid and respective amounts of testing vectors. Cells were plated as indicated and treated with respective inducers for defined periods of time. Luciferase activity was measured as suggested by manufacturer's protocol (Steady-Glo $^{\mathrm{TM}}$ or Dual-Luciferase ${ }^{\mathrm{TM}}$ Reporter Assay Systems, Promega), using a FlexStation 3 Microplate Reader (Molecular Devices).

\section{Mass spectrometry (LC-MS/MS)}

IP eluates were adjusted to $200 \mu \mathrm{l}$ with $50 \mathrm{mM}$ ammonium bicarbonate. Then, 4 ul Tris(2-carboxyethyl) phosphine (TCEP) was added to each sample and proteins were reduced at $60^{\circ} \mathrm{C}$ for $30 \mathrm{~min}$. Iodoacetamide was added (to $20 \mathrm{mM}$ ) and proteins were alkylated at $30 \mathrm{~min}$ at room temperature in the dark. Mass spectrometry grade trypsin (Promega) was added (1:20 ratio) for overnight digestion at $37^{\circ} \mathrm{C}$. After digestion, formic acid was added to the peptide solution (to $2 \%$ ), followed by desalting with Microtrap (Thermo Scientific) and then online analysis of peptides by high-resolution and high-accuracy LC-MS/ MS consisting of a Michrom HPLC, a 15-cm Michrom Magic C18 column, a low-flow ADVANCED Michrom MS source, and a LTQ-Orbitrap XL (Thermo Fisher Scientific). A 120 min gradient of $10-30 \%$ B $(0.1 \%$ formic acid, $100 \%$ acetonitrile) was used to separate the peptides. The total LC time was $140 \mathrm{~min}$. The LTQ-Orbitrap XL was set to scan precursors in the Orbitrap followed by data-dependent MS/MS of the top 10 precursors.

The LC-MSMS raw data were submitted to Sorcerer Enterprise v.3.5 release (Sage-N Research Inc.) with SEQUEST algorithm as the search program for peptide/ protein identification. The differential spectral count analysis and proteolytic profile mapping was performed by QTools, an open source in-house tool developed for automated differential peptide/protein spectral count analysis and Gene Ontology [69].

\section{ACKNOWLEDGEMENTS}

The authors thank J. Xing, K. Liu, K. Motamedchaboki, K. Welsh, R. Williams, S-I. Matsuzawa and Y. Matsuzawa (SBMRI, La Jolla, CA) for their assistance with aspects of this work. We are also grateful to the members of the UCI NCI SPECS consortium who contributed to the prostate sample collection, the assignment of Gleason scores, and generation of TMAs: D. Mercola (Department of Pathology and Laboratory Medicine, University of California Irvine, CA), J.W. Rodriguez (University of California, San Diego, CA), P. Carpenter (University of California, Irvine Medical Center, CA) and S. Krajewski (SBMRI, La Jolla, CA). We also thank A. Shabaik (University of California, San Diego, CA) for providing CRPC specimens and S. P. Balk (BIDMC, Boston, MA) for providing DNA constructs. This project was supported by NIH funds (R01 AI056324, U01 CA114810, P01 CA177322 and R01 CA164679).

\section{CONFLICT OF INTEREST}

No potential conflicts of interest were disclosed. Dr. Reed is an employee of the Roche Group.

\section{REFERENCES}

1. da Silva HB, Amaral EP, Nolasco EL, de Victo NC, Atique R, Jank CC, Anschau V, Zerbini LF and Correa RG. Dissecting Major Signaling Pathways throughout the Development of Prostate Cancer. Prostate cancer. 2013; 2013:920612.

2. Chen CD, Welsbie DS, Tran C, Baek SH, Chen R, Vessella $\mathrm{R}$, Rosenfeld MG and Sawyers CL. Molecular determinants 
of resistance to antiandrogen therapy. Nat Med. 2004; 10(1):33-39.

3. Li TH, Zhao H, Peng Y, Beliakoff J, Brooks JD and Sun Z. A promoting role of androgen receptor in androgensensitive and -insensitive prostate cancer cells. Nucleic acids research. 2007; 35(8):2767-2776.

4. Kanneganti TD, Lamkanfi M and Nunez G. Intracellular NOD-like receptors in host defense and disease. Immunity. 2007; 27(4):549-559.

5. Ting JP, Lovering RC, Alnemri ES, Bertin J, Boss JM, Davis BK, Flavell RA, Girardin SE, Godzik A, Harton JA, Hoffman HM, Hugot JP, Inohara N, Mackenzie A, Maltais LJ, Nunez G, et al. The NLR gene family: a standard nomenclature. Immunity. 2008; 28(3):285-287.

6. Creagh EM and O'Neill LA. TLRs, NLRs and RLRs: a trinity of pathogen sensors that co-operate in innate immunity. Trends Immunol. 2006; 27(8):352-357.

7. Murray PJ. NOD proteins: an intracellular pathogenrecognition system or signal transduction modifiers? Curr Opin Immunol. 2005; 17(4):352-358.

8. Martinon F and Tschopp J. Inflammatory caspases and inflammasomes: master switches of inflammation. Cell Death Differ. 2007; 14(1):10-22.

9. Petrilli V, Dostert C, Muruve DA and Tschopp J. The inflammasome: a danger sensing complex triggering innate immunity. Curr Opin Immunol. 2007; 19(6):615-622.

10. Tattoli I, Travassos LH, Carneiro LA, Magalhaes JG and Girardin SE. The Nodosome: Nod1 and Nod2 control bacterial infections and inflammation. Semin Immunopathol. 2007; 29(3):289-301.

11. Carneiro L, Magalhaes J, Tattoli I, Philpott D and Travassos L. Nod-like proteins in inflammation and disease. J Pathol. 2008; 214(2):136-148.

12. Davis BK, Wen H and Ting JP. The inflammasome NLRs in immunity, inflammation, and associated diseases. Annu Rev Immunol. 2011; 29:707-735.

13. da Silva Correia J, Miranda Y, Austin-Brown N, Hsu J, Mathison J, Xiang R, Zhou H, Li Q, Han J and Ulevitch RJ. Nod1-dependent control of tumor growth. Proc Natl Acad Sci U S A. 2006; 103(6):1840-1845.

14. Allen IC, Wilson JE, Schneider M, Lich JD, Roberts RA, Arthur JC, Woodford RM, Davis BK, Uronis JM, Herfarth HH, Jobin C, Rogers AB and Ting JP. NLRP12 suppresses colon inflammation and tumorigenesis through the negative regulation of noncanonical NF-kappaB signaling. Immunity. 2012; 36(5):742-754.

15. Kutikhin AG. Role of NOD1/CARD4 and NOD2/CARD15 gene polymorphisms in cancer etiology. Hum Immunol. 2011; 72(10):955-968.

16. Kang MJ, Heo SK, Song EJ, Kim DJ, Han SY, Han JH, Kim BY and Park JH. Activation of Nod1 and Nod2 induces innate immune responses of prostate epithelial cells. Prostate. 2012.

17. Kufer TA, Fritz JH and Philpott DJ. NACHT-LRR proteins
(NLRs) in bacterial infection and immunity. Trends Microbiol. 2005; 13(8):381-388.

18. Correa RG, Milutinovic S and Reed JC. Roles of NOD1 (NLRC1) and NOD2 (NLRC2) in innate immunity and inflammatory diseases. Bioscience reports. 2012; 32(6):597608.

19. Inohara, Chamaillard, McDonald $\mathrm{C}$ and Nunez G. NODLRR proteins: role in host-microbial interactions and inflammatory disease. Annu Rev Biochem. 2005; 74:355383.

20. Carneiro LA, Travassos LH and Girardin SE. Nod-like receptors in innate immunity and inflammatory diseases. Ann Med. 2007; 39(8):581-593.

21. Stein C, Caccamo M, Laird G and Leptin M. Conservation and divergence of gene families encoding components of innate immune response systems in zebrafish. Genome Biol. 2007; 8(11):R251.

22. Zou H, Henzel WJ, Liu X, Lutschg A and Wang X. Apaf1, a human protein homologous to $\mathrm{C}$. elegans CED-4, participates in cytochrome c-dependent activation of caspase-3. Cell. 1997; 90(3):405-413.

23. Heinemeyer T, Wingender E, Reuter I, Hermjakob H, Kel AE, Kel OV, Ignatieva EV, Ananko EA, Podkolodnaya OA, Kolpakov FA, Podkolodny NL and Kolchanov NA. Databases on transcriptional regulation: TRANSFAC, TRRD and COMPEL. Nucleic acids research. 1998; 26(1):362-367.

24. Matzuk MM and Lamb DJ. The biology of infertility: research advances and clinical challenges. Nat Med. 2008; 14(11):1197-1213.

25. Guth SI and Wegner M. Having it both ways: Sox protein function between conservation and innovation. Cellular and molecular life sciences : CMLS. 2008; 65(19):3000-3018.

26. Yuan X, Lu ML, Li T and Balk SP. SRY interacts with and negatively regulates androgen receptor transcriptional activity. J Biol Chem. 2001; 276(49):46647-46654.

27. Brothman AR, Wilkins PC, Sales EW and Somers KD. Metastatic properties of the human prostatic cell line, PPC1 , in athymic nude mice. The Journal of urology. 1991; 145(5):1088-1091.

28. Ting JP, Willingham SB and Bergstralh DT. NLRs at the intersection of cell death and immunity. Nat Rev Immunol. 2008; 8(5):372-379.

29. Oettgen P, Finger E, Sun Z, Akbarali Y, Thamrongsak U, Boltax J, Grall F, Dube A, Weiss A, Brown L, Quinn G, Kas K, Endress G, Kunsch C and Libermann TA. PDEF, a novel prostate epithelium-specific ets transcription factor, interacts with the androgen receptor and activates prostatespecific antigen gene expression. J Biol Chem. 2000; 275(2):1216-1225.

30. Sood AK, Kim H and Geradts J. PDEF in prostate cancer. Prostate. 2012; 72(6):592-596.

31. Sood AK, Saxena R, Groth J, Desouki MM, Cheewakriangkrai C, Rodabaugh KJ, Kasyapa CS and 
Geradts J. Expression characteristics of prostate-derived Ets factor support a role in breast and prostate cancer progression. Human pathology. 2007; 38(11):1628-1638.

32. Ngan S, Stronach EA, Photiou A, Waxman J, Ali S and Buluwela L. Microarray coupled to quantitative RT-PCR analysis of androgen-regulated genes in human LNCaP prostate cancer cells. Oncogene. 2009; 28(19):2051-2063.

33. Dehm SM and Tindall DJ. Alternatively spliced androgen receptor variants. Endocrine-related cancer. 2011; 18(5):R183-196.

34. Balk SP, Ko YJ and Bubley GJ. Biology of prostate-specific antigen. Journal of clinical oncology : official journal of the American Society of Clinical Oncology. 2003; 21(2):383391.

35. Jasavala R, Martinez H, Thumar J, Andaya A, Gingras AC, Eng JK, Aebersold R, Han DK and Wright ME. Identification of putative androgen receptor interaction protein modules: cytoskeleton and endosomes modulate androgen receptor signaling in prostate cancer cells. Molecular \& cellular proteomics : MCP. 2007; 6(2):252271.

36. Burnstein KL. Regulation of androgen receptor levels: implications for prostate cancer progression and therapy. Journal of cellular biochemistry. 2005; 95(4):657-669.

37. Reddy GP, Barrack ER, Dou QP, Menon M, Pelley R, Sarkar FH and Sheng S. Regulatory processes affecting androgen receptor expression, stability, and function: potential targets to treat hormone-refractory prostate cancer. Journal of cellular biochemistry. 2006; 98(6):1408-1423.

38. Rajendran KV, Zhang J, Liu S, Kucuktas H, Wang X, Liu H, Sha Z, Terhune J, Peatman E and Liu Z. Pathogen recognition receptors in channel catfish: I. Identification, phylogeny and expression of NOD-like receptors. Developmental and comparative immunology. 2012; 37(1):77-86.

39. Lange C, Hemmrich G, Klostermeier UC, Lopez-Quintero JA, Miller DJ, Rahn T, Weiss Y, Bosch TC and Rosenstiel P. Defining the origins of the NOD-like receptor system at the base of animal evolution. Molecular biology and evolution. 2011; 28(5):1687-1702.

40. Laing KJ, Purcell MK, Winton JR and Hansen JD. A genomic view of the NOD-like receptor family in teleost fish: identification of a novel NLR subfamily in zebrafish. BMC evolutionary biology. 2008; 8:42.

41. Hu Y, Ding L, Spencer DM and Nunez G. WD-40 repeat region regulates Apaf-1 self-association and procaspase-9 activation. J Biol Chem. 1998; 273(50):33489-33494.

42. Bolton KL, Tyrer J, Song H, Ramus SJ, Notaridou M, Jones C, Sher T, Gentry-Maharaj A, Wozniak E, Tsai YY, Weidhaas J, Paik D, Van Den Berg DJ, Stram DO, Pearce CL, Wu AH, et al. Common variants at 19p13 are associated with susceptibility to ovarian cancer. Nature genetics. 2010; 42(10):880-884.

43. Garcia-Closas M, Couch FJ, Lindstrom S, Michailidou
K, Schmidt MK, Brook MN, Orr N, Rhie SK, Riboli E, Feigelson HS, Le Marchand L, Buring JE, Eccles D, Miron $\mathrm{P}$, Fasching PA, Brauch H, et al. Genome-wide association studies identify four ER negative-specific breast cancer risk loci. Nature genetics. 2013; 45(4):392-398, 398e391-392.

44. Michailidou K, Hall P, Gonzalez-Neira A, Ghoussaini M, Dennis J, Milne RL, Schmidt MK, Chang-Claude J, Bojesen SE, Bolla MK, Wang Q, Dicks E, Lee A, Turnbull C, Rahman N, Breast, et al. Large-scale genotyping identifies 41 new loci associated with breast cancer risk. Nature genetics. 2013; 45(4):353-361, 361e351-352.

45. Pharoah PD, Tsai YY, Ramus SJ, Phelan CM, Goode EL, Lawrenson K, Buckley M, Fridley BL, Tyrer JP, Shen H, Weber R, Karevan R, Larson MC, Song H, Tessier DC, Bacot F, et al. GWAS meta-analysis and replication identifies three new susceptibility loci for ovarian cancer. Nature genetics. 2013; 45(4):362-370, 370e361-362.

46. Prasad A, Merico D, Thiruvahindrapuram B, Wei J, Lionel AC, Sato D, Rickaby J, Lu C, Szatmari P, Roberts W, Fernandez BA, Marshall CR, Hatchwell E, Eis PS and Scherer SW. A discovery resource of rare copy number variations in individuals with autism spectrum disorder. G3. 2012; 2(12):1665-1685.

47. Gallant NM, Baldwin E, Salamon N, Dipple KM and Quintero-Rivera F. Pontocerebellar hypoplasia in association with de novo 19p13.11p13.12 microdeletion. American journal of medical genetics Part A. 2011; 155A(11):2871-2878.

48. Lech M, Avila-Ferrufino A, Skuginna V, Susanti HE and Anders HJ. Quantitative expression of RIG-like helicase, NOD-like receptor and inflammasome-related mRNAs in humans and mice. Int Immunol. 2010; 22(9):717-728.

49. Slim R and Wallace EP. NLRP7 and the Genetics of Hydatidiform Moles: Recent Advances and New Challenges. Frontiers in immunology. 2013; 4:242.

50. Kanai Y, Hiramatsu R, Matoba S and Kidokoro T. From SRY to SOX9: mammalian testis differentiation. Journal of biochemistry. 2005; 138(1):13-19.

51. Tricoli JV, Yao JL, D'Souza SA and Bracken RB. Detection of sex-region Y (SRY) transcripts in human prostate adenocarcinoma and benign prostatic hypertrophy. Genes, chromosomes \& cancer. 1993; 8(1):28-33.

52. Perinchery G, Sasaki M, Angan A, Kumar V, Carroll P and Dahiya R. Deletion of Y-chromosome specific genes in human prostate cancer. The Journal of urology. 2000; 163(4):1339-1342.

53. Jordan JJ, Hanlon AL, Al-Saleem TI, Greenberg RE and Tricoli JV. Loss of the short arm of the Y chromosome in human prostate carcinoma. Cancer genetics and cytogenetics. 2001; 124(2):122-126.

54. Thomsen MK, Ambroisine L, Wynn S, Cheah KS, Foster CS, Fisher G, Berney DM, Moller H, Reuter VE, Scardino P, Cuzick J, Ragavan N, Singh PB, Martin FL, Butler CM, Cooper CS, et al. SOX9 elevation in the prostate promotes 
proliferation and cooperates with PTEN loss to drive tumor formation. Cancer Res. 2010; 70(3):979-987.

55. Krajewska M, Turner BC, Shabaik A, Krajewski S and Reed JC. Expression of BAG-1 protein correlates with aggressive behavior of prostate cancers. Prostate. 2006; 66(8):801-810.

56. Krajewska M, Kitada S, Winter JN, Variakojis D, Lichtenstein A, Zhai D, Cuddy M, Huang X, Luciano F, Baker CH, Kim H, Shin E, Kennedy S, Olson AH, Badzio A, Jassem J, et al. Bcl-B expression in human epithelial and nonepithelial malignancies. Clinical cancer research : an official journal of the American Association for Cancer Research. 2008; 14(10):3011-3021.

57. Ghadersohi A, Sharma S, Zhang S, Azrak RG, Wilding GE, Manjili MH and Li F. Prostate-derived Ets transcription factor (PDEF) is a potential prognostic marker in patients with prostate cancer. Prostate. 2011; 71(11):1178-1188.

58. Turner DP, Findlay VJ, Moussa O, Semenchenko VI, Watson PM, LaRue AC, Desouki MM, Fraig M and Watson DK. Mechanisms and functional consequences of PDEF protein expression loss during prostate cancer progression. Prostate. 2011; 71(16):1723-1735.

59. Chen H, Nandi AK, Li X and Bieberich CJ. NKX-3.1 interacts with prostate-derived Ets factor and regulates the activity of the PSA promoter. Cancer Res. 2002; 62(2):338340.

60. Prescott J and Coetzee GA. Molecular chaperones throughout the life cycle of the androgen receptor. Cancer letters. 2006; 231(1):12-19.

61. Hudson AM and Cooley L. Phylogenetic, structural and functional relationships between WD- and Kelch-repeat proteins. Sub-cellular biochemistry. 2008; 48:6-19.

62. Faustin B, Lartigue L, Bruey JM, Luciano F, Sergienko E, Bailly-Maitre B, Volkmann N, Hanein D, Rouiller I and Reed JC. Reconstituted NALP1 inflammasome reveals twostep mechanism of caspase-1 activation. Mol Cell. 2007; 25(5):713-724.

63. Faustin B, Chen Y, Zhai D, Le Negrate G, Lartigue L, Satterthwait A and Reed JC. Mechanism of Bcl-2 and Bcl$\mathrm{X}(\mathrm{L})$ inhibition of NLRP1 inflammasome: loop domaindependent suppression of ATP binding and oligomerization. Proc Natl Acad Sci U S A. 2009; 106(10):3935-3940.

64. Tiscornia G, Singer O, Ikawa M and Verma IM. A general method for gene knockdown in mice by using lentiviral vectors expressing small interfering RNA. Proc Natl Acad Sci U S A. 2003; 100(4):1844-1848.

65. Tiscornia G, Singer O and Verma IM. Production and purification of lentiviral vectors. Nature protocols. 2006; 1(1):241-245.

66. Krajewska M, Kim H, Shin E, Kennedy S, Duffy MJ, Wong YF, Marr D, Mikolajczyk J, Shabaik A, Meinhold-Heerlein I, Huang X, Banares S, Hedayat H, Reed JC and Krajewski $\mathrm{S}$. Tumor-associated alterations in caspase-14 expression in epithelial malignancies. Clinical cancer research : an official journal of the American Association for Cancer Research. 2005; 11(15):5462-5471.

67. Pio R, Jia Z, Baron VT, Mercola D and Cancer UNSCotSPftEoCS-P. Early growth response 3(Egr3) is highly over-expressed in non-relapsing prostate cancer but not in relapsing prostate cancer. PLoS One. 2013; 8(1):e54096.

68. Krajewska M, Smith LH, Rong J, Huang X, Hyer ML, Zeps N, Iacopetta B, Linke SP, Olson AH, Reed JC and Krajewski S. Image analysis algorithms for immunohistochemical assessment of cell death events and fibrosis in tissue sections. The journal of histochemistry and cytochemistry : official journal of the Histochemistry Society. 2009; 57(7):649-663.

69. Brill LM, Motamedchaboki K, Wu S and Wolf DA. Comprehensive proteomic analysis of Schizosaccharomyces pombe by two-dimensional HPLC-tandem mass spectrometry. Methods. 2009; 48(3):311-319. 